\title{
THE ACCURATE DETERMINATION OF THE GASOLINE CONTENT OF NATURAL GAS AND THE ANALYTICAL SEPARATION OF NATURAL GASES BY ISOTHERMAL FRACTIONAL DISTILLATION
}

\author{
By Martin Shepherd
}

\section{ABSTRACT}

This paper describes a method for the accurate determination of gasoline in natural gas. The determination involves a special separation of the natural gas by fractional distillation at low temperatures and pressures. A recombination of the resultant fractions is made in such a way that it is possible to determine the maximum amount of hydrocarbon condensate present in the original gas which possesses any given vapor pressure at any given temperature. Special forms of apparatus are used for separating the higher boiling constituents and determining their liquid volume to $0.001 \mathrm{ml}$. Apparatus and procedures are described in detail, analytical results given, and a direct comparison made with existing field and laboratory methods. The analytical separation of natural gases and their commercial condensates is also discussed. The paper as a whole is intended to be a simple instruction book for those who wish to engage in such work.

\section{CONTENTS}

I. Need for and scope of the method.

II. Development of a definition of the term "natural gasoline" content of natural gas.

III. Principle of the analytical method.

IV. Apparatus

1. Gas burettes

2. Liquid burette

3. Pipettes for gas analysis

1152

4. Pumps . .

1152

5. Distilling tubes

1154

6. Temperature control _...

7. Differential manometer._._.

8. Auxiliary vacuum pumps_.._.

9. Stopcocks._._.

10. Kind of glass_.

11. Assembly _._.

(a) Complete unit...... 1159

(b) Simplified unit...... 1159

(c) Experimental unit............. 1161 
V. General procedures

1. Preparation of apparatus for a determination

2. Order of procedures during a single determination.

3. Measurement of gas volumes

4. Transfer of gas volumes

1163

5. Operation of the distillation train

1164

6. Measurement of vapor pressures.

7. Determination of purities of the distillates

1165

1168

1169

VI. Separation of gas sample by fractional distillation _ _._.

1. Isobutane, propane, and lower boiling components_..... 1170

2. Butane fraction

3. Pentane and higher boiling components._._. 1173

4. Fractionation charts..._._._._.

(a) Types of gases separated

(b) Key to interpretation of fractionation charts...... 1174

(c) Discussion of charts._._._._._. 1175

VII. Recombination of fractions for determination of natural gasoline content.

1. Measurement of pentane fraction _.

2. Addition of butane fraction

VIII. Analytical results and accuracy obtainable

1. Vapor-pressure curves of mixtures of pentane and butane fractions and their analytical significance............-

2. Comparison of measurement of natural gasoline content as determined in vapor and liquid phase................

3. Comparison of results obtained by present methods with those obtained by existing field and laboratory methods...-

\section{NEED FOR AND SCOPE OF THE METHOD}

Of the various existing field and laboratory methods for the determination of natural gasoline in natural gas ${ }^{1}$ three deserve mention. They are the compression-cooling method, the oil-absorption method, and the charcoal-adsorption method. There are many variations of these three methods, and the individual operator is apt to introduce modifications suitable to his peculiar needs. It is very difficult to obtain satisfactory agreement between the methods, and apparently it is almost equally difficult for different operators to obtain satisfactory analytical checks by use of the same method.

The Natural Gas Association of America recognized this discordant state and appointed a committee to study the problem and formulate standard methods of test. The committee's investigation led to a partial and tentative standardization of the three methods already mentioned $^{2}$ and a critical study of their accuracy which the present paper will report in part. This study has clearly shown the need of a reference or umpire method for the determination of natural gasoline.

\footnotetext{
1 For a description of these methods see Burrell, Recovery of Gasoline from Natural Gas, ch. 10, A. C. S. Monograph Series, Chemical Catalog Co., New York.

2 Code of the Natural Gas Association of America, No. 1. Report of the Committee on Standard Testing for Gessoline. The Natural Gas Association of America, 903 Oliver Building, Pittsburgh, Pa.
} 
The method here proposed is intended for reference, standardization, and investigational work. The relatively complicated equipment and procedures required make the method unsuited for routine field testing or ordinary plant control. It possesses its own distinct value, however, whenever new processes are to be investigated or actual plant efficiencies determined. It may be used to study and standardize ordinary methods of plant control or resorted to in case of umpire decisions involving questions of the true natural gasoline content of natural gases. It is the only known method capable of analytically separating natural gases and quantitatively determining their constituents. As such, it is being successfully used by a number of commercial laboratories which have been in touch with the present work during the past several years.

\section{DEVELOPIIENT OF A DEFINITION OF THE TERM "NATURAL GASOLINE" CONTENT OF NATURAL GAS}

In order to develop an analytical method for the quantitative determination of some one substance in a mixture of other substances, it is obviously necessary to define clearly the nature of the one substance sought. Strangely enough, this usually simple requirement has presented a most perplexing problem in the present instance, for entire agreement has never been reached in the natural-gas industry as to just what is meant by the term "gasoline," or more particularly "natural gasoline," since we are directly concerned with a product of that name extracted from natural gas. It is generally agreed that "natural gasoline" consists of a mixture of hydrocarbons which may be condensed from natural gas, and that this condensate should be commercially manageable; that is, capable of safe transportation from the place of its origin to wherever it may find its final useusually the blending with refinery and cracked "gasolines." But just what the exact chemical composition of this condensate may be is a question which can not be answered. Because of the different character of natural gases from various fields, and because of the difference in local requirements of refiners, what is considered "natural gasoline" in Pennsylvania may not be "natural gasoline" in Texas, and a California or Wyoming "natural gasoline" may not be recognized as such in either of the first two localities. Nor, for that matter, does perplexity cease with the consideration of the geographical environment of this problematic compound. A perfectly respectable "natural gasoline" born of the winter months might find its reputation for sobriety entirely reversed during the hot days of summer. So it is that geographical and meterological conditions conspire to confuse the identity of the substance which we must determine by analysis without knowing just what it is we are to determine. 
With this troublesome situation as a beginning, it may seem difficult to develop a definition of the term "natural gasoline" content. However, a workable definition, based on the two factors of chemical composition and vapor pressure, seems possible and desirable.

Vapor pressure becomes one criterion, since present Interstate Commerce Commission shipping regulations are formulated with respect to this property. ${ }^{3}$ With an arbitrary classification of petroleum condensates once established on such a basis, the producer of natural gasolines must then be directly concerned with the vapor pressure of his product.

On the other hand, it is obviously possible to produce hydrocarbon condensates of an infinite variety of percentage compositions, all of which may possess an identical vapor pressure at some fixed temperature. Natural gas is composed largely of the saturated hydrocarbons, of which the proportion ordinarily making up the condensate called "natural gasoline" is of the order of magnitude of 1 or 2 per cent of the total gas. The vapor pressures of these components at once establish the fact that pentane and other hydrocarbons of the series of higher boiling points may be safely included as properly belonging to the condensate to be called natural gasoline. The further fact is evident that some butane may be included in such a mixture without exceeding the vapor pressure requirements. In practice small percentages of propane or even ethane are actually held in solution with the desirable components, although present developments in "stabilization," which include the use of a simple rectifying column, are tending to correct this error. It is apparent that small traces of propane will appreciably increase the saturation pressure of such a mixture and cause inexcusable "weathering" losses. Rafferty ${ }^{4}$ and others have advanced interesting data to show the relative changes of vapor pressure caused by butane and propane present in condensates of pentane and higher boiling hydrocarbons. Whether or not these data are entirely correct, they certainly show the right trend.

From this simple consideration of vapor pressures it follows that for any one natural gas of definite composition there is a definite maximum amount of condensate, possessing a fixed vapor pressure $(p)$ at some fixed temperature $(T)$, which can be extracted from this gas, and that when this maximum yield is obtained the composition of the condensate is perfectly definite. The percentage composition and volume of this maximum amount of condensate will depend entirely on the original composition of the gas and the arbitrary saturation pressure and temperature selected. In the case of a "natural gasoline" this condensate will contain all of the pentane and hydro-

${ }^{3}$ Bureau of Explosives, Pamphlet No.9, pp. 50-51, published December, 1922, by Bureau of Explosives, 30 Vesey Street, New York, N. Y.

4 J. A. Rafferty, Nat. Petroleum News, p. 35; A pr. 25, 1923. 
carbons of higher boiling points occurring in the original gas and, in addition, as much normal butane as may be incorporated without exceeding the fixed vapor pressure $(p)$ at the temperature $(T)$. It will include no isobutane, propane, or hydrocarbons of lower boiling points. Such a condensate is a definite substance which can be determined quantitatively.

Accepting this concept as a reasonable basis of identification, we may then define the natural gasoline content as the hydrocarbon condensate derived from natural gas which is composed of the total percentages of pentane plus higher boiling hydrocarbons occurring as vapors in the natural gas, plus a sufficient percentage of normal butane to cause the total condensate to possess a saturation pressure $(p)$ at a temperature $(T)$.

The method described in this paper may be used to determine this natural gasoline content. The assignment of desirable values for $(p)$ and $(T)$ is not attempted, this matter being in the hands of the industry. Rather, in the present work, $(p)$ was determined over a relatively wide range with $(T)$ held constant, so that it is possible to compute the amount of this maximum condensate possessing any convenient saturation pressure. These data are useful in connection with blending or other special problems of the industry. Further, $(p)$ may be determined for various values of $(T)$. The value $100^{\circ} \mathrm{F}$. was used for $(T)$ in the present work, being selected with reference to shipping regulations. If it is desired to accept the corresponding limiting figure of $10 \mathrm{lbs}$./in. ${ }^{2}$ for vapor tension, we are in a position to definitely state the amounts of "natural gasoline," and analogously those of "casing-head gasoline" (not over $20 \mathrm{lbs}$./in." at $100^{\circ} \mathrm{F}$.) and "liquified petroleum gas" (over $20 \mathrm{lbs} . / \mathrm{in} .^{2}$ at $100^{\circ} \mathrm{F}$.) in the natural gas.

\section{PRINCIPLE OF THE ANALYTICAL METHOD}

With the development of a definition for the term "natural gasoline," it is possible to establish an analytical method for the determination of the natural gasoline content of any natural gas. The analysis will obviously require that the natural gas be separated into three fractions:

1. Isobutane, propane, and hydrocarbons of lower boiling points, together with nitrogen and traces of oxygen, carbon dioxide, and helium, if present.

2. Normal butane.

3. Pentanes and hydrocarbons of higher boiling points.

Fractions 1 and 2 may be measured in the vapor phase. Fraction 3 may be determined in the vapor phase by difference from the original sample, and further measured directly in the liquid phase by means of especially designed apparatus. The vapor pressure of fraction 3 may then be measured at some fixed temperature. 
Measured increments of fraction 2 may be recondensed into fraction

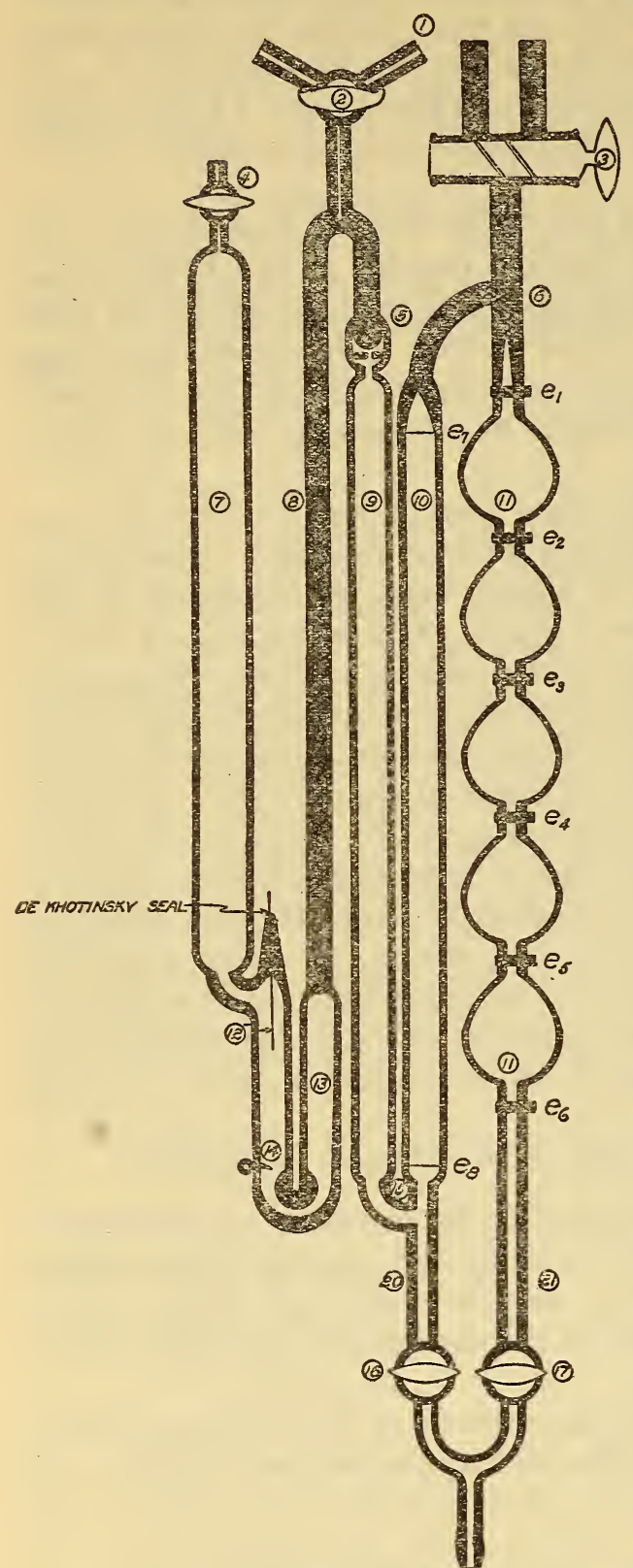

FIgURe 1.-Gas burette with vernier scale and without gas connection to compensator (substitute for $B_{2}$ of Figure 10)

a development of that of Shepherd
3 , the increase of vapor pressure at the fixed temperature being noted for each addition. In this manner the percentage of hydrocarbon condensate present in the original gas may be plotted against its vapor pressure at any fixed temperature. Furthermore, the maximum amount present in the original gas which will possess the vapor pressure noted at the fixed temperature is given by this plot, since the composition of this condensate represents the hydrocarbons in direct order of their boiling points from high to low. A curve plotted from such data discloses this maximum percentage for any desired vapor pressure at the fixed temperature. The percentages may be expressed in the vapor phase and a factor applied to translate these to gallons per million cubic feet, or they may be expressed directly in the liquid phase in the same unit. It will be shown later that the two methods check within the accuracy demanded by natural-gas engineers.

In order to separate the natural gas into the fractions noted, it is necessary to employ a method of fractional distillation at low temperatures and pressures. The method here used is and Porter. ${ }^{5}$ Several inac- 
curacies of the former method are corrected and the apparatus modified so as to effect more efficient separations and increase the ease of manipulation.

\section{APPARATUS}

The apparatus consists of units for measuring gas and liquid volumes, manometers for measuring saturation pressures, pipettes for absorption and combustion analyses (if desired), pumps for the transference of gas volumes, and a system of distilling bulbs for effecting the separation of the gas sample. These must be assembled to form one single unit, the various parts of which are interconnected by fused glass joints. Auxiliary apparatus consists of suitable devices for controlling and measuring low temperatures, liquid-air containers, and one or more mechanical vacuum pumps, such as those employing gears or eccentric cams immersed in oil.

\section{GAS BURETTES}

The burette ${ }^{6}$ used in the present investigation was one designed without gas connection to the compensator. It is of the bulbed type, and measurements of fractional volumes are made on a side arm provided with a scale and vernier. The glass parts are illustrated in Figure 1. The accuracy is $0.01 \mathrm{ml}$ or better. It was used

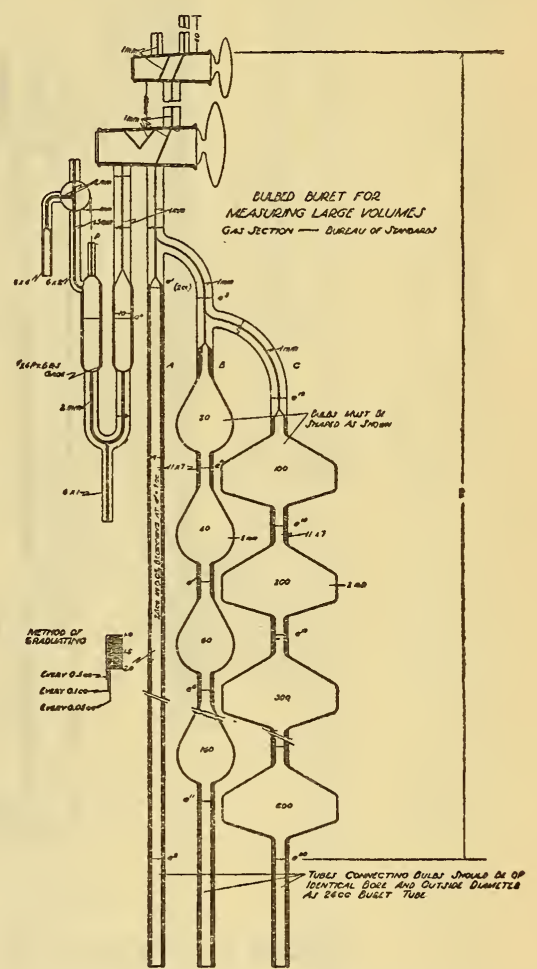

Figure 2.-Gas burette, $B_{2}$ of Figure 10 in connection with a calibrated bulb of 1 liter capacity in order to lessen the number of volume measurements required.

A somewhat preferable form for the present work is shown in Figure 2. It is a bulbed burette of large capacity, capable of measuring both the original sample and any fraction thereof at one step. This obviously decreases the time required for a determination. The drawing indicates the construction of the burette alone. A compensator should be connected to the manometer.

\footnotetext{
6 This burette is described in B. S. Sci. Paper No. 559, A Burette for the Accurate Measurement of Gas
} Volumes without Gas Connection to a Compensator, by E. R. Weaver and Martin Shepherd. 


\section{LIQUID BURETTE}

A special weight burette ${ }^{7}$ was used for the measurement of the pentane and higher boiling hydrocarbons. (Fig. 3.) Determinations may be made with an accuracy of $0.001 \mathrm{ml}$.

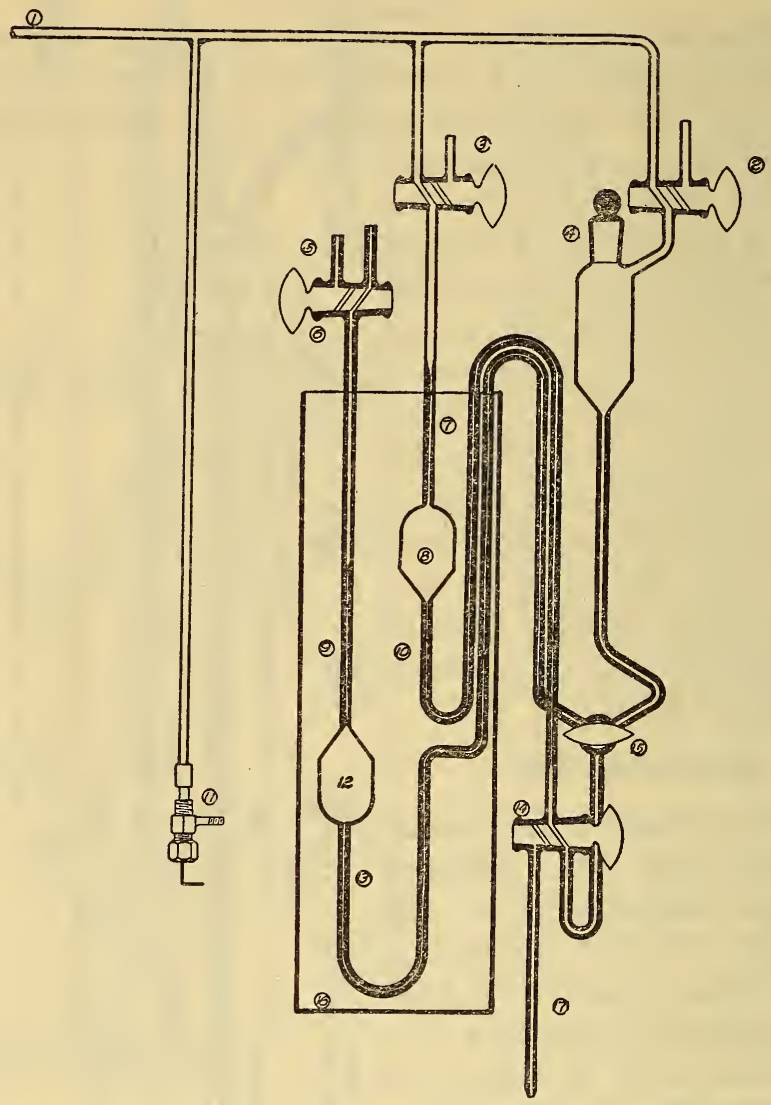

Figure 3.-Burette for the measurement of small liquid volumes, $B_{1}$ of Figure 10

\section{PIPETTES FOR GAS ANALYSIS}

While any suitable type may be used, the preferred forms are the Weaver-Ledig combustion pipette ${ }^{8}$ and the Dennis-Friedrichs absorption pipette. ${ }^{9}$ These are unnecessary if it is not desired to make a complete analysis of the natural gas, which involves the estimation of nitrogen in a nitrogen-methane fraction.

7 The burette and its operation are described in detail in B. S. Sci. Paper No. 555, A Weight Burette for the Micromeasurement of Liquid Volumes, by Martin Shepherd.

8 J. Ind. Eng. Chem., 12, p. 368; 1920;

${ }^{9}$ Dennis, Gas Analysis, Macmillan Co. of New York, p. 81; 1918. 


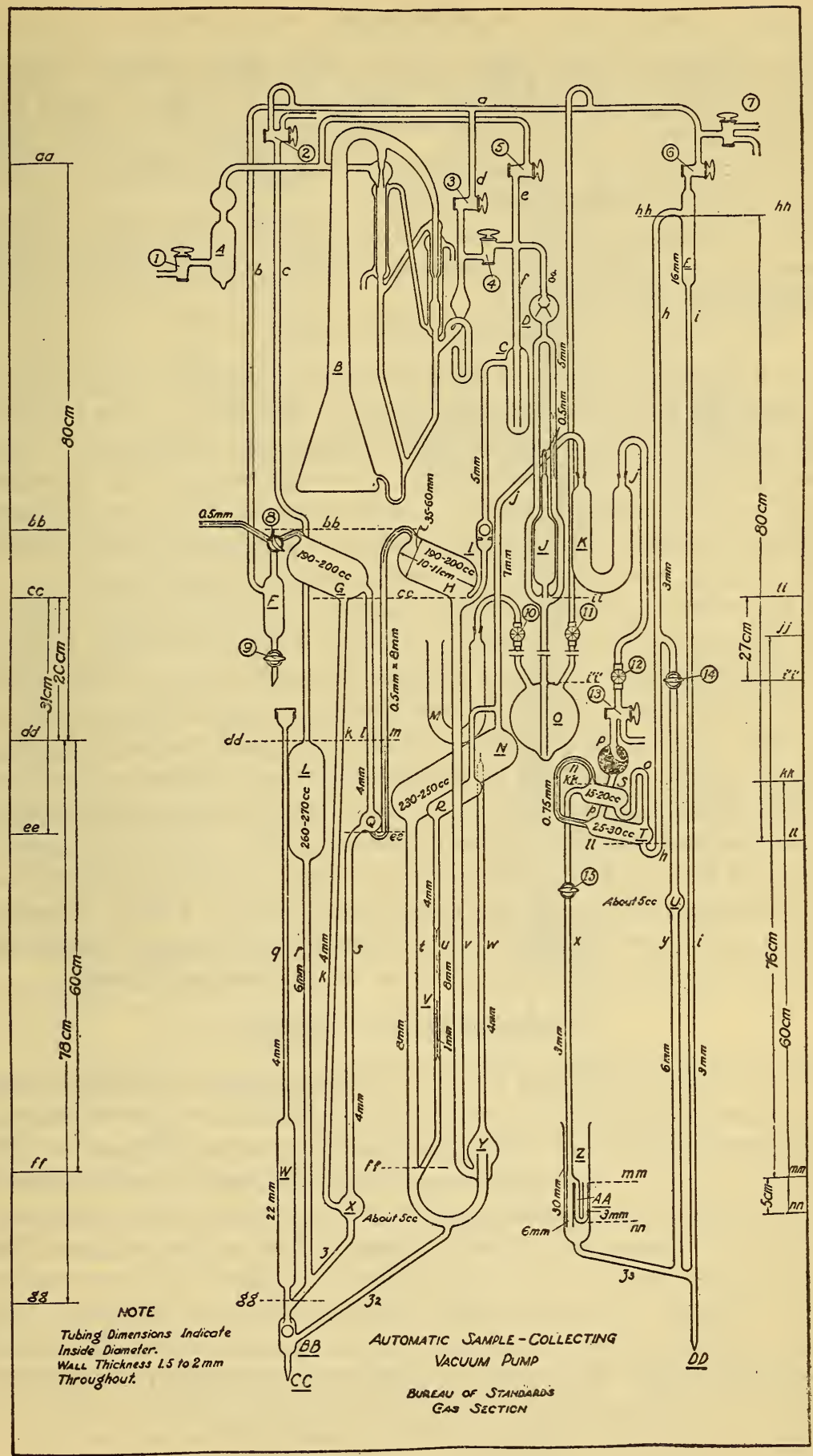

FIgURe 4.-Automatic Töpler pump, $V_{2}$ of Figure 10 


\section{PUMPS}

An automatic Töpler pump ${ }^{10}$ (fig. 4) was used to collect nitrogen and a portion of the methane. It acted as a backing pump to a Stimson mercury vapor pump. ${ }^{11}$ This arrangement permits high speed in the transfer of gas volumes. A manually operated Töpler pump may be substituted if desired.

The transference of gas was accomplished for the most part by means of a system of condensing bulbs operating at liquid air temperatures.

\section{DISTILLING TUBES}

(a) For the separation of lower boiling constituents and final cuts the distilling tube illustrated in Figure 5 was used. It is provided with a sealed-in thermocouple and a barometric manometer. (Indicated in sketch.) The cotton filter at the bottom of this tube prevents the mechanical carrying over of frozen particles in the gas stream. Without this filter it was found possible to carry water through four such tubes in series when they were immersed in liquid air. ${ }^{12}$

(b) For the separation of higher boiling constituents the rectifying tube (ifg. 6) was used. This is in reality a small rectifying column. It is filled with copper balls of uniform diameter (about $3 \mathrm{~mm}$ ), which provide the proper spacing for satisfactory reflux action in a tube of this size. The good thermal conductivity and possibly the heat capacity of the copper aid in maintaining the temperature gradient, which is effected by supplying a small current to a nichrome heating element wound about the tube in a gradually opening helix as indicated, the heat so added balancing the loss of heat to the liquid air which surrounds the tube but is held from contact with it by an air bath. Any desired temperature gradient may be imposed upon the column by properly spacing the turns of the heating element.

\section{TEMPERATURE CONTROL}

This has been described for the rectifying type of distilling tube. The copper cylinder constructed as shown in Figure 7 provides satisfactory temperature control for the distilling tube of Figure 5. The cylinder is bored to fit snugly around this tube, and a smaller parallel well accommodates a thermocouple. The whole unit hangs suspended in a Dewar tube, the perforated plate at the top providing support over the mouth of the Dewar. A fiber collar secures the copper cylinder to this plate and acts as a thermal insulator. The bottom of the cylinder projects to within an inch of the bottom of the Dewar tube. The whole is cooled to the desired temperature

10 E. R. Weaver and Martin Shepherd, J. Am. Chem. Soc., 50, p. 1829; 1928.

11 Stimson, J. Wash. Acad. Sci., \%, p. 477; 1917.

12 The distillation of glycerine through a common $U$ tube at liquid hydrogen temperatures has also been observed by C. W. Kanolt at the Bureau of Standards. 
with liquid air, and the slow vaporization of a small amount of liquid air at the bottom of the Dewar tube, combined with the high heat capacity of the copper block, is sufficient to hold the temperature to within $0.5^{\circ}$ of any desired value over the range $-160^{\circ}$ to $-80^{\circ} \mathrm{C}$. during the time consumed by an average distillation. Further temperature adjustment is effected by the occasional addition of small amounts of liquid air through the perforated top plate. The thermal conductivity of the copper block is quite sufficient to maintain the desired uniformity of temperature under these conditions.

The device has been used for several years and replaces the cooled hydrocarbon bath often used for this purpose. The latter presents a distinct fire hazard, since the confining Dewar tube may explode at any time and in so doing practically atomize the liquid contents, which may in turn ignite from any accidental source, possibly even a static spark from the disrupting glass of the Dewar tube itself. If a liquid bath is preferred, a nonflammable mixture, such as described by Kanolt, ${ }^{13}$ may be used.

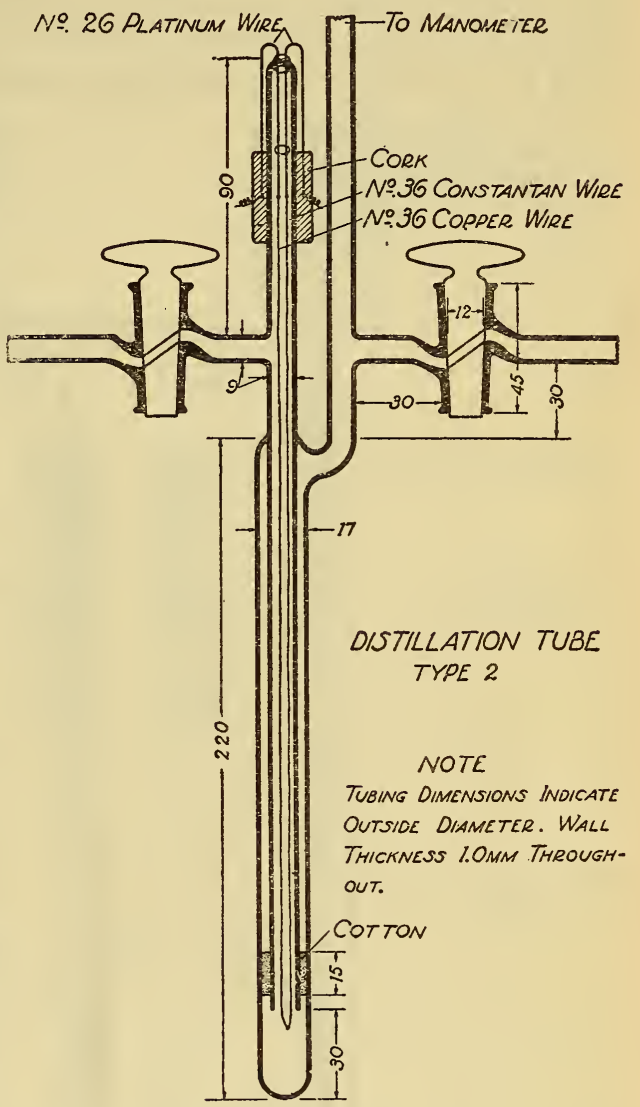

Figdre 5.-Plain distillation tube, $I I-V$ of Figure 10

Condensing temperatures of approximately $-210^{\circ} \mathrm{C}$. are obtained by boiling liquid air under reduced pressure. ${ }^{14}$

Temperatures are measured by copper-constantan couples made from carefully calibrated No. 36 wire used in connection with a pre-

${ }^{13}$ B. S. Sci. Paper No. 520, Nonflammable Liquids for Cryostats, by C. W. Kanolt, or International Critical Tables, 1, p. 61 .

14 The operator who may not be familiar with the handling of liquid air will find an excellent description of this technique given by Claude in his book, Liquid Air, Oxygen and Nitrogen (translated by Henry E. P. Cottrell, J. and A. Churchill, London, 1913, Pt. III, Ch. VIII, p. 202). This author describes not only the storage and manipulation of liquid air, but also gives a very interesting account of a number of experiments based upon its unusual physical and chemical properties. 
cision potentiometer. When making vapor pressure measurements, temperatures were measured by a multiple couple.

Dewar tubes of approximately 1-pint size are ordinarily used for cryostat-bath containers, except for the rectifying type of distilling tube, which requires a larger size (approximately 1 quart). Six-pint Dewar flasks are convenient for the laboratory storage of liquid air. If the liquid air is to be shipped or transported to the laboratory from

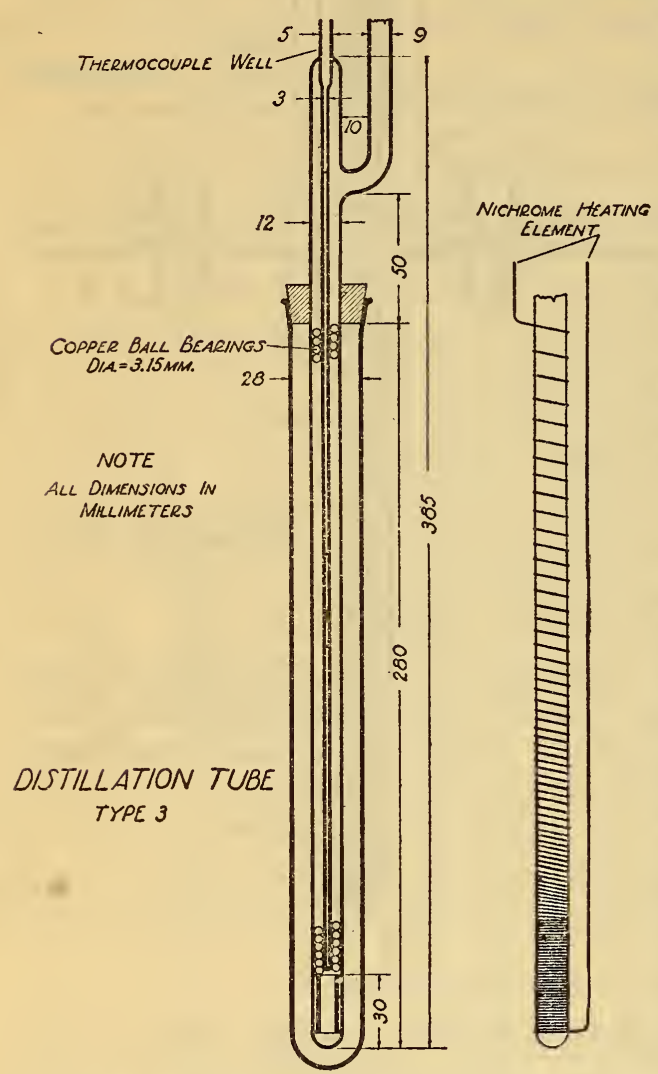

FigURe 6.-Rectifying distillation tube, tube I of Figure 10 any distance, 15 or 25 liter metal containers are recommended. These maintain their own insulating vacuum by means of a charcoal cartridge held at the temperature of the liquid air. They are provided with a long, narrow neck, so that conduction down the metal is not a serious factor.

\section{DIFFERENTIAL MANOM- ETER}

A simple differential manometer for the determination of the purities of distillates is illustrated in Figure 8. It is not shown in the assembly drawing which follows, but should be connected to the distillation train at a point just beyond tube $V$ and in the same line as bulbs $C_{3}-C_{5}$. (See fig. 10.) Stopcocks 1 and 2 of the manometer serve to open or close bulbs $B_{1}$ and $B_{2}$ to this portion of the distillation train. The manometer $M$ is filled with clean mercury, and the levels are read by means of the hollow micrometer screws $A_{1}$ and $A_{2}$. These are constructed and calibrated exactly like a standard micrometer gauge, except that they are made hollow to accommodate the arms of the manometer to which they are cemented. The verniers read to $0.01 \mathrm{~mm}$, and repeated trials have shown that readings of the position of the mercury menisci may be made with this precision. A diffused light is placed back of the manometer, and this 
B. S. Journal of Research, RP75

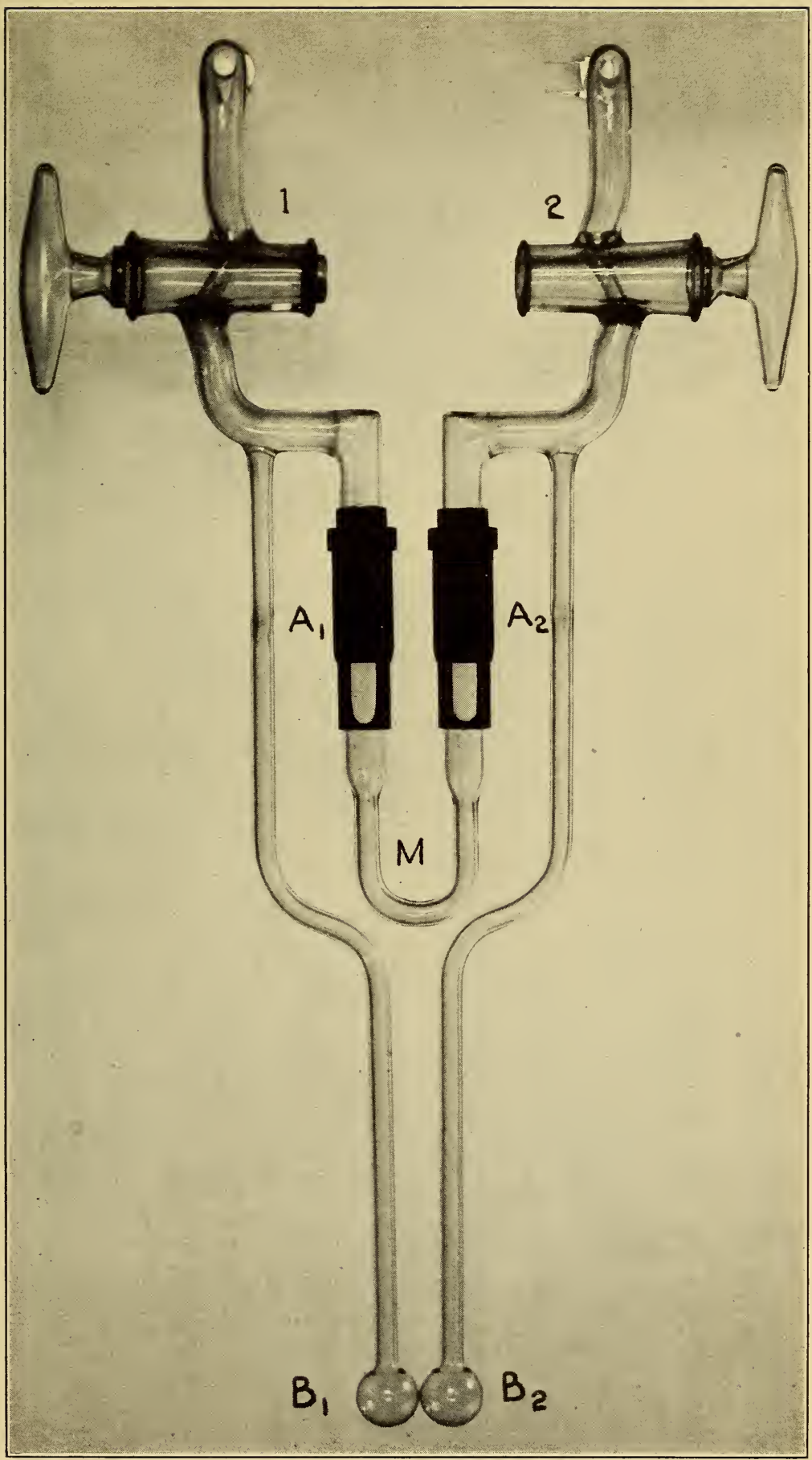

FIgURE 8.-A differential manometer for measuring the purities of distillates 
is screened so that only the exposed portions of the glass arms within the slits formed by the micrometer casings are illuminated. The screw collar is adjusted to form an interference pattern at the top of the meniscus.

\section{AUXILIARY VACUUM PUMPS}

One or more oil-immersed gear or eccentric cam vacuum pumps are required. Three is a convenient number, although one can be made to perform all the necessary work. If three are used, one should provide reduced pressure over the liquid air baths; a second should be used as a backing pump for the mercury vapor pump; and a third connected to the various mercury reservoirs to raise the large volumes of mercury they contain.

\section{STOPCOCKS}

Since the procedure requires operation in part at very low pressures, it is necessary to eliminate all rubber connections and use only fused glass joints. The stopcocks located in parts of the apparatus subjected to high vacuum present sources of potential leaks and must, therefore, be very carefully ground. It has been found best to use simple cocks of the so-called " 2 -way" type rather than " 3 -way," T, or $120^{\circ}$ cocks. A hollow-blown key ground to the so-called "mirror finish," of the dimensions shown in Figure $9(A)$, is quite dependable. These should be lubricated with a grease similar to the "high vacuum" type de-
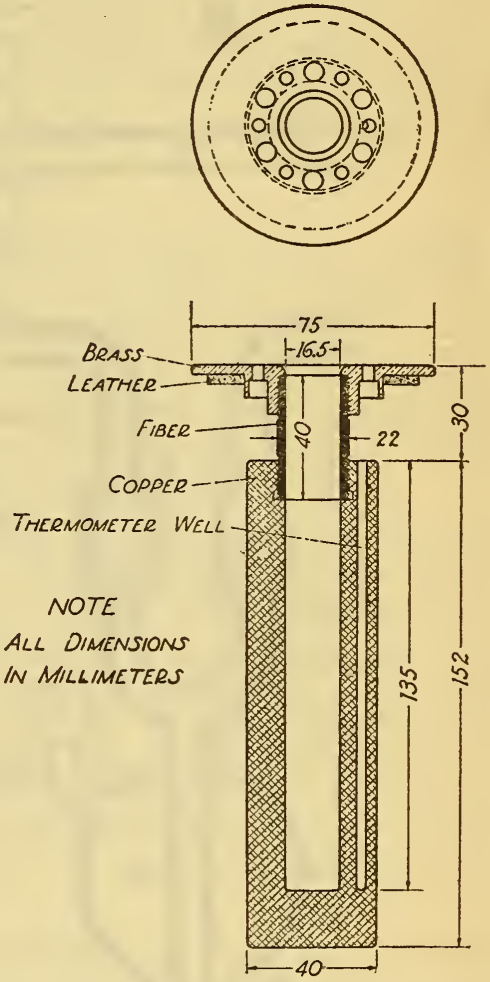

FIGURE 7.-Temperature control unit for plain type distillation tube scribed by Shepherd and Ledig. ${ }^{15}$ With such high-grade cocks suitably lubricated, no difficulty has been experienced in maintaining high vacuum over long periods.

Some investigators prefer a mercury shut-off rather than a stopcock for high vacuum apparatus. A convenient design is shown in Figure

15 Rubber Stopcock Lubricants for High Vacuum and Other Uses, by Martin Shepherd and Paul Ledig Ind. Eng. Chem., 19, p. 1056; 1927. 
$9(B)$. It has the advantage over the ordinary mercury shut-off of functioning over wide-pressure variations and at the same time presenting a compact unit that requires little space in the assembly of a large apparatus.

The outlets $O_{1}$ and $O_{2}$ are fused into the line where the gas flow is to be interrupted. Mercury from the reservoir $R$ discharges into the $\mathrm{U}$ tube when pressure is applied through the air inlet of the auxiliary needle valve $V$. This mercury is withdrawn by connecting $R$ to a
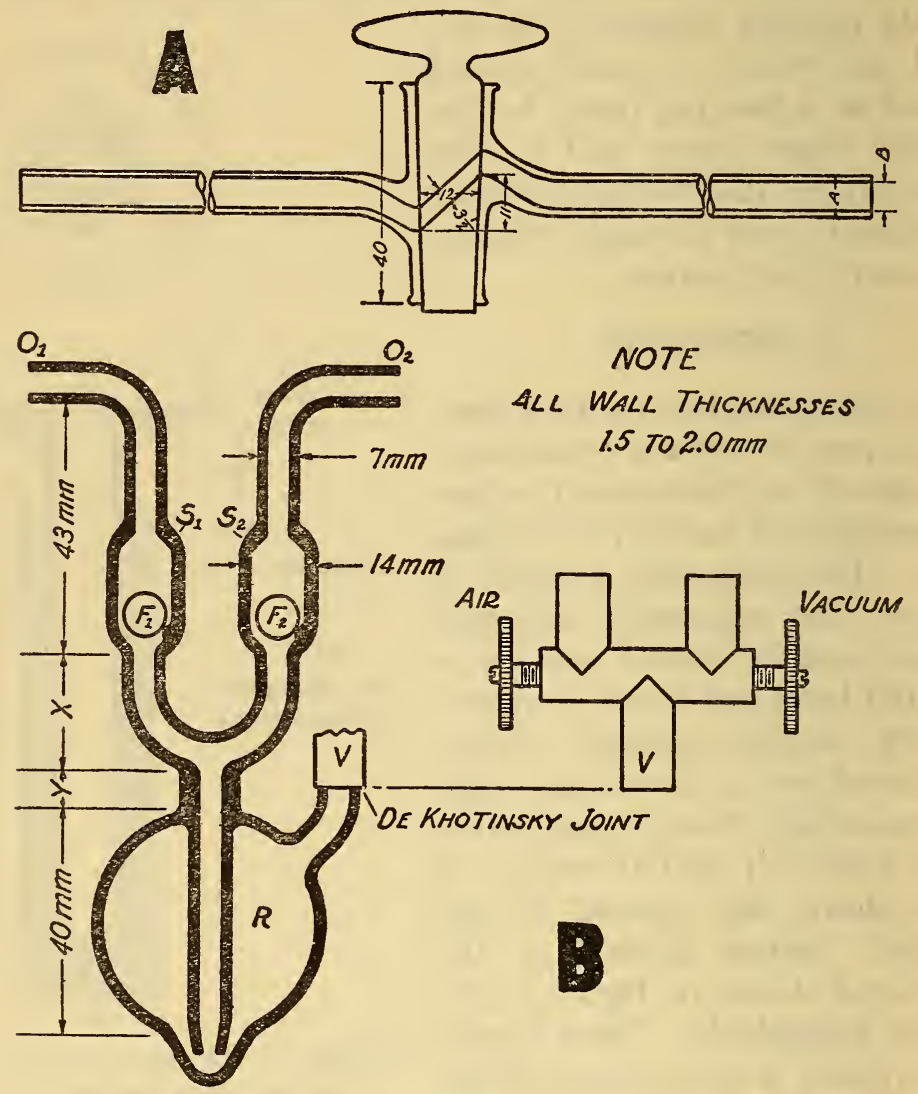

NOTE

4LL WALL THICKNESSES

$1.5702 .0 \mathrm{~mm}$

Figure 9

$A$, Stopcock for high vacuum work; $B$, mercury shut-off for high vacuum apparatus

vacuum line through the second outlet of the valve $V$. The floats $F_{1}$ and $F_{2}$ are solid glass balls ground spherical between rotating plates. They seat against $45^{\circ}$ grindings $S_{1}$ and $S_{2}$, preventing mercury from being carried over into the apparatus. Such float valves have never been found to leak if properly ground.

The pressure applied at the air inlet of the needle valve determines the range over which the shut-off will operate. The dimensions of the glass $U$ tube may be enlarged to suit the requirements of high vacuum work. 


\section{KIND OF GLASS}

The unit may be constructed of Pyrex glass, although the author prefers a good grade of soft glass. The reasons for this are: (1) The tendency of Pyrex to "pinhole," even when carefully worked in an oxy-gas flame. This causes considerable trouble in high vacuum work, al though it is quite possible to construct a satisfactorily tight apparatus of Pyrex. (2) The formation of an insulating film of gas between the liquid and the glass prevents the breaking of soft glass bulbs immersed in liquid air. No difficulty with breakage of this sort has been experienced when well-annealed soft glass bulbs were used, and Pyrex presents no real advantage in this respect in the present instance. The mercury vapor pump must, of course, be constructed from Pyrex stock, and this can be sealed into a soft glass unit with graded seals.

\section{ASSEMBLY}

(a) Complete Unit.-The apparatus is assembled as diagrammatically indicated in Figure 10. This drawing has been simplified with a key to lettering, so that the character of its individual parts are at once apparent. The detailed drawings of the various parts given in the preceding figures ( 1 to 6 , inclusive) have been lettered so that direct reference can be made to the drawing of the assembly. The identity of each part is thus easily established.

(b) Simplified Unit.-The assembly drawing indicates the most convenient form of the apparatus and is strongly recommended in case extended work of this character is to be done. The apparatus has been considerably simplified for the use of commercial laboratories, however, and this simplified form has found favor with several laboratories which are investigating natural gasoline and refining problems. It is shown by two photographs (figs. 11 and 12), of which the former is the completely assembled unit and the latter a detailed view of the distillation train. A meter stick at the left of the photograph provides a scale.

For purposes of comparative study Figure 11 has been lettered to correspond directly to the lettering of Figure 10. The comparison will reveal a number of alterations appearing on the simplified apparatus. The distillation train remains unchanged except for the omission of a MicLeod gauge. This simplification is not to be recommended except in cases where so-called "dry" natural gases are to be separated. The $P_{2} O_{5}$ drier is sealed as a $T$ to the exit of the distillation train and may be turned to the line when the unit is standing idle. The mercury vapor pump is retained, but the system $V_{2} R S_{1}$ is substituted for the automatic Töpler pump. This system amounts to a manually operated Töpler pump without a barometric or float valve on the inlet. The bulb $\nabla_{2}$ is of 1-liter capacity and acts not only as the backing pump for the mercury vapor pump but 


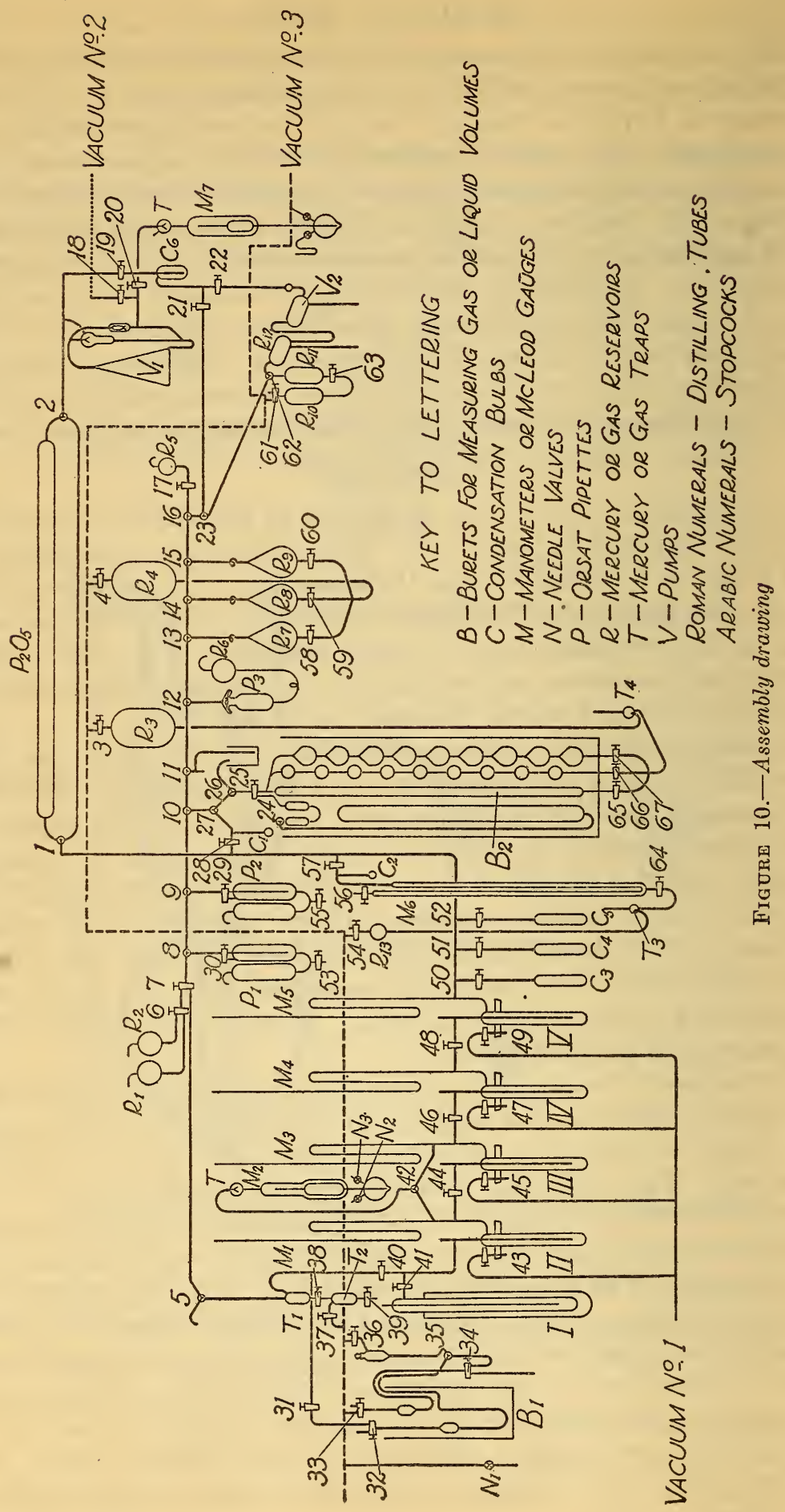




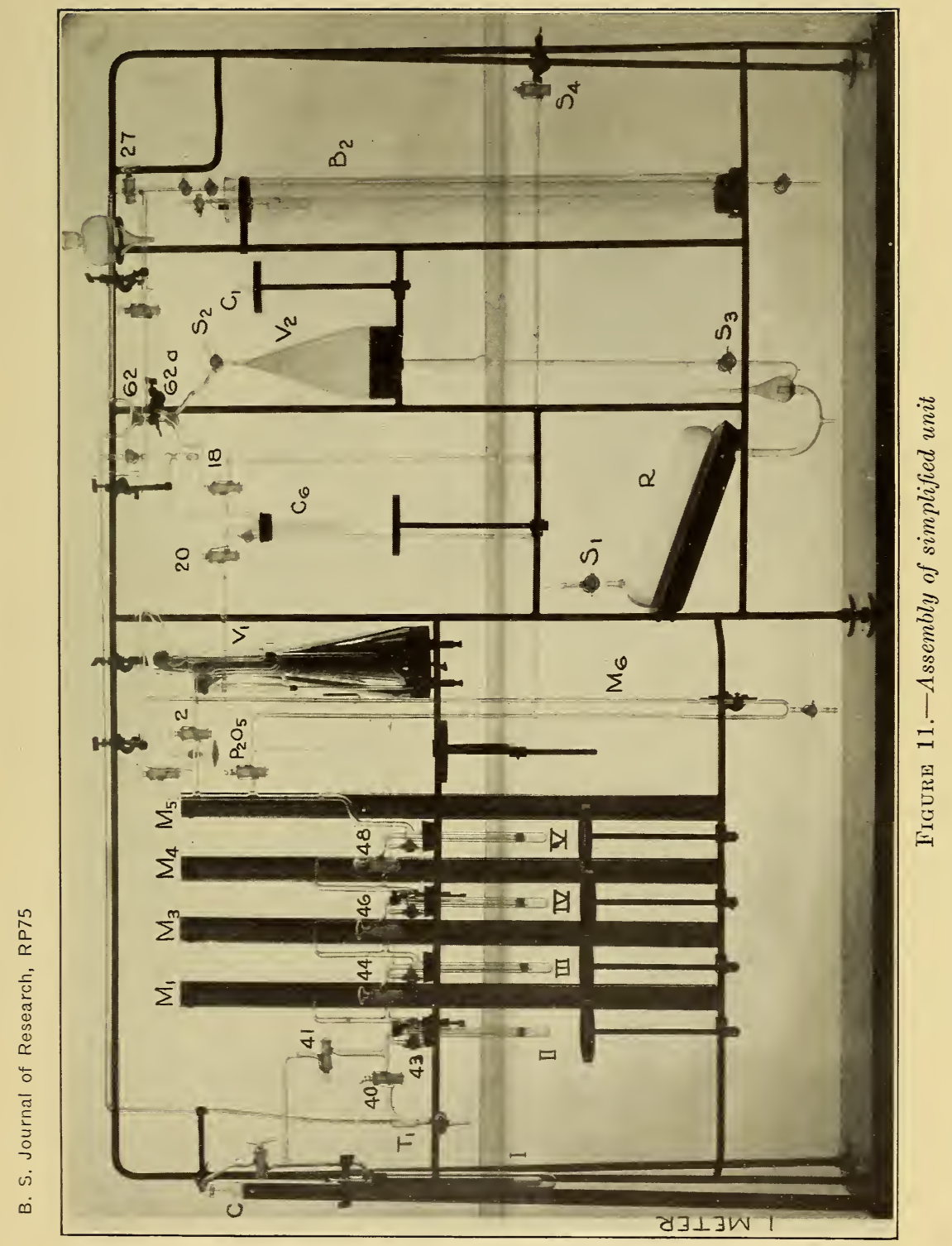


B. S. Journal of Research, RP75

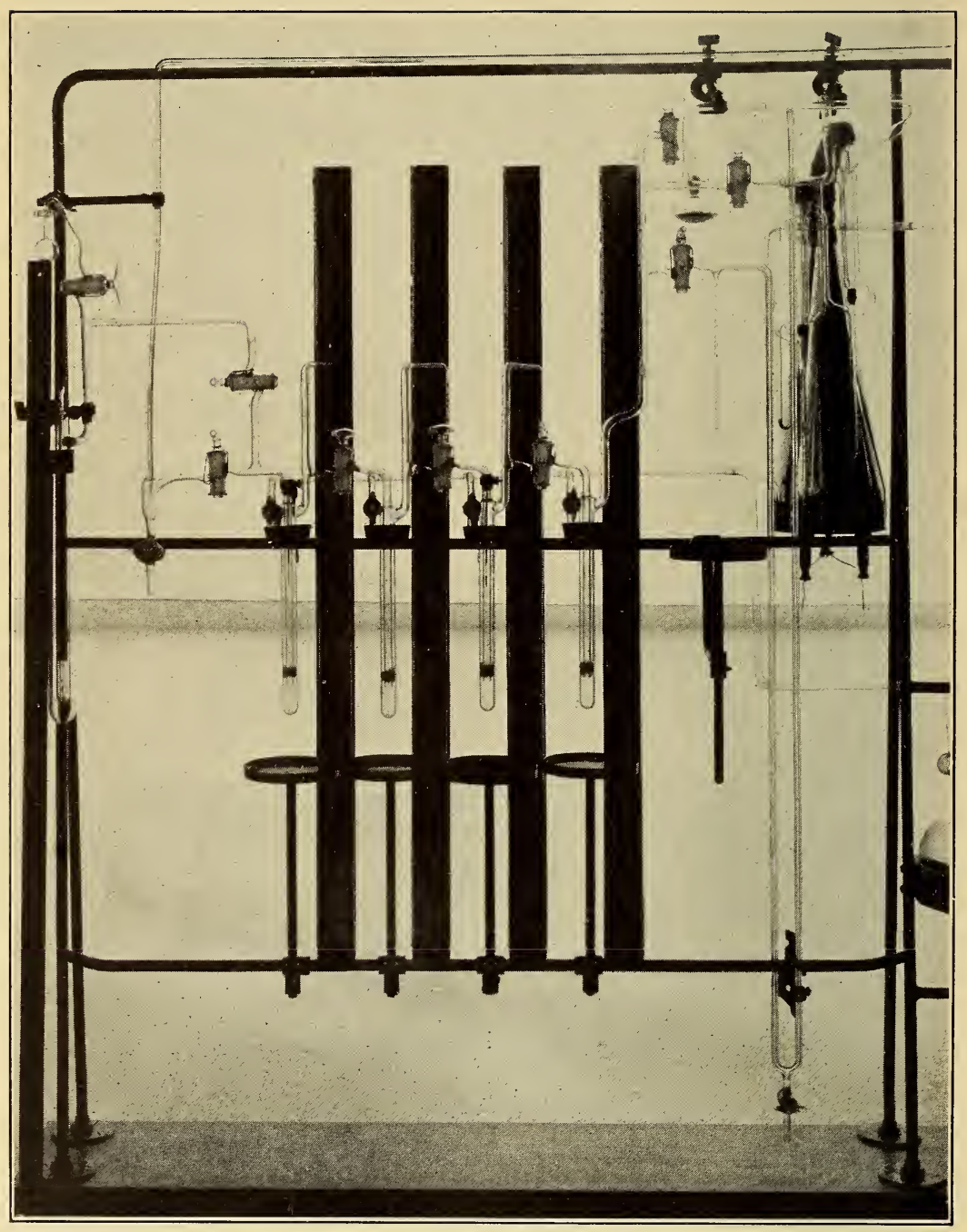

FIGURE 12.-Detail of the distillation train of simplified unit 


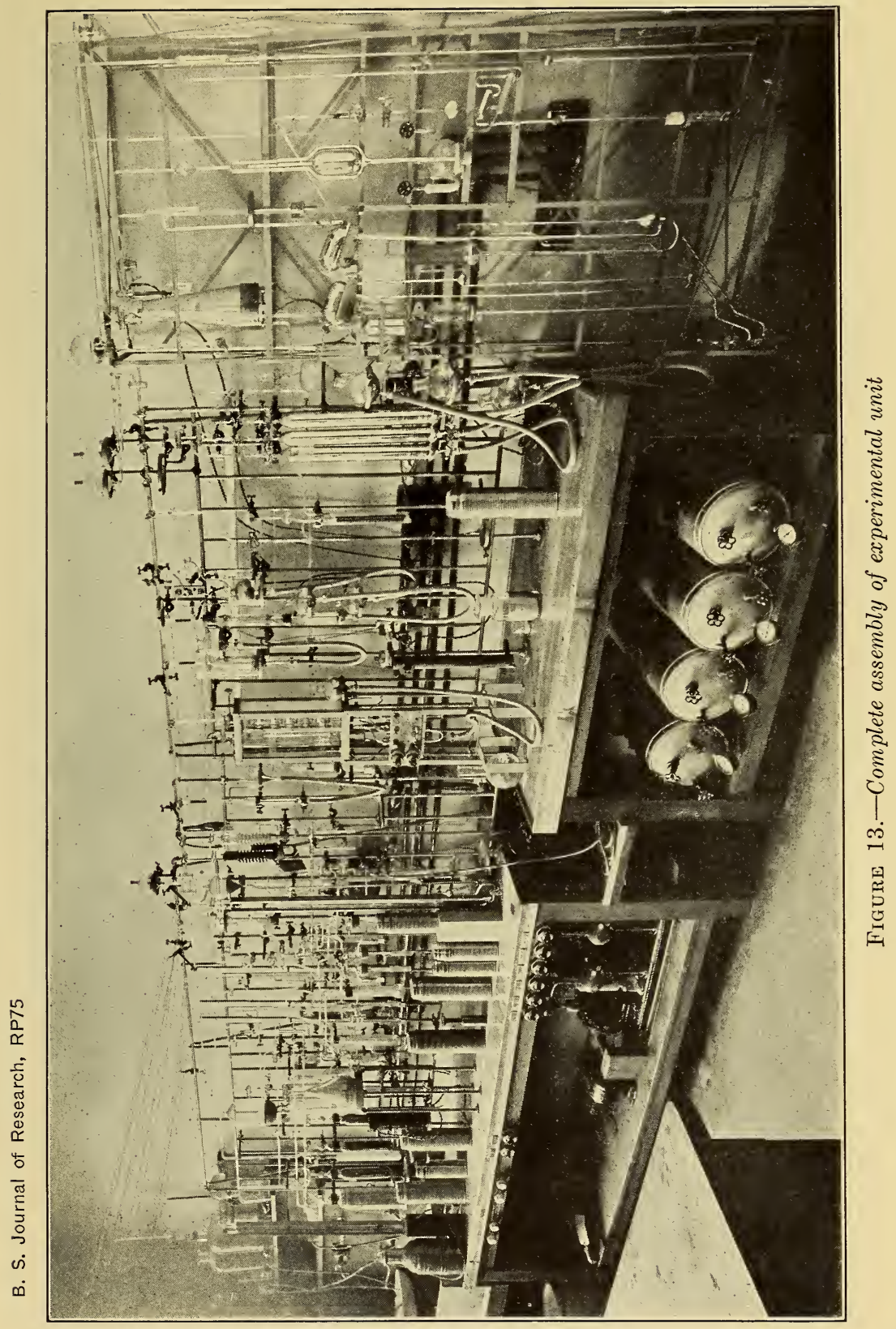


B. S. Journal of Research, RP75

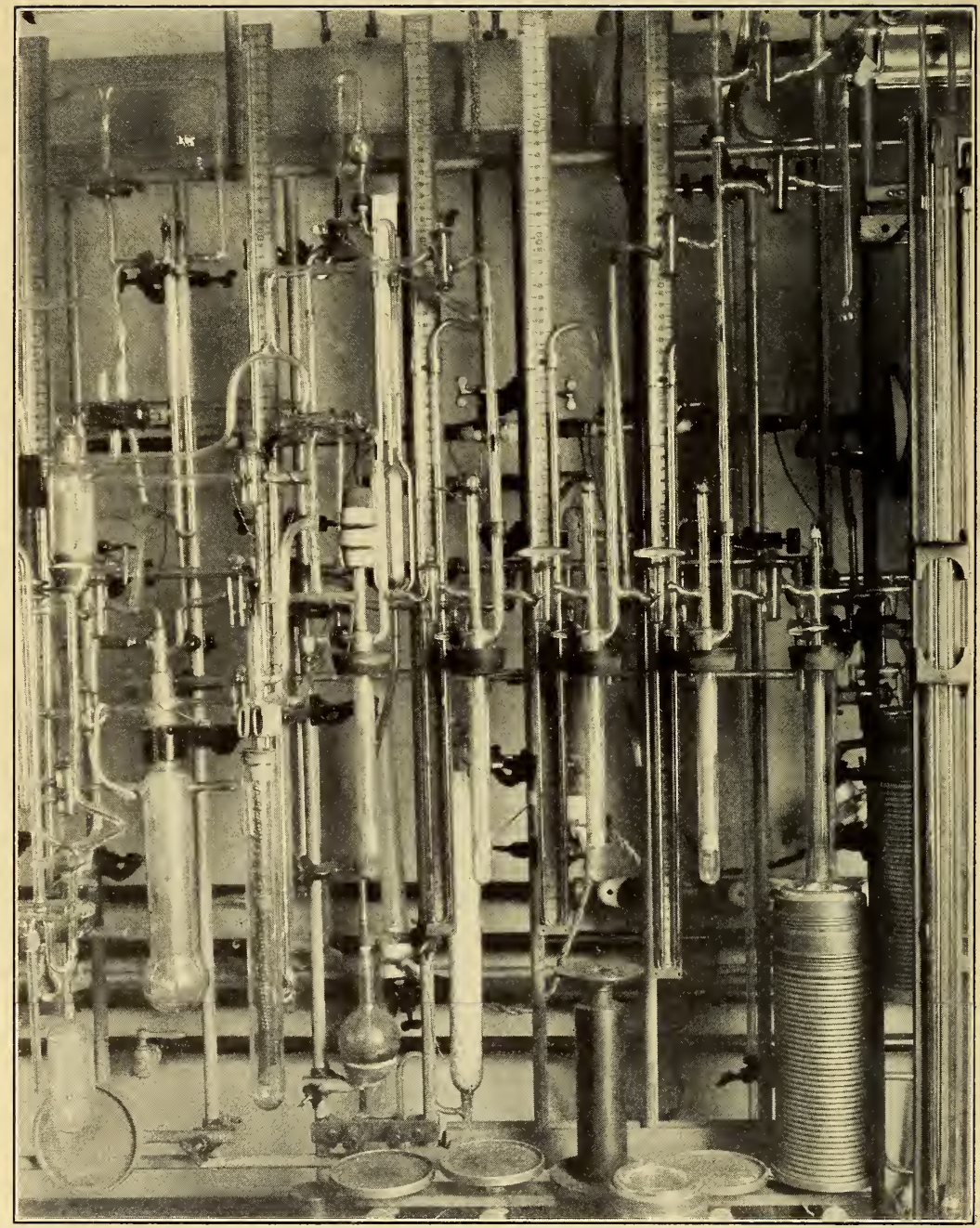

FIgURE 14.-Detail of the distillation train of experimental unit 
also as the burette for the measurement of the original gas sample. When acting as the collecting pump, mercury from the reservoir $R$ is forced into $V_{2}$ by pressure applied through the 3 -way stopcock $S_{1}$, stopcock $S_{2}$ being turned to the atmosphere. When mercury has completely filled $V_{2}, S_{3}$ is closed, $S_{2}$ opened to $C_{6}$, and $S_{3}$ reopened with vacuum applied to $R$ through $S_{1}$. The gas taken into $V_{2}$ is then forced directly into the burette $B_{2}$ by again applying pressure to $R$ and adjusting stopcocks $62 \mathrm{a}, 62$, and 27 . Since the bulb $V_{2}$ is of very large capacity and has only $C_{6}$ and the connections to the pump $V_{1}$ to evacuate, a very few such operations are sufficient for initial evacuation or the removal of the nitrogen-methane fraction. All other pumping is done by direct condensation from the exit of the train to bulb $C_{1}$, stopcock 2 being closed and 28 opened for this purpose.

The simplified apparatus has no liquid or gas reservoirs and no combustion or absorption pipettes. The gas burette supplied is of the ordinary $100 \mathrm{ml}$ compensated type, which increases the number of volume measurements of the various fractions. The liquid burette is omitted, determinations being made entirely in the vapor phase. A direct measurement of natural gasoline content is accordingly impossible. The vapor pressure manometer $M_{6}$ is retained. A bulb $C$ for the introduction of liquid samples has been added. Only one oil-immersed vacuum pump is used as an auxiliary. This is connected to the line terminating in stopcock $S_{4}$.

The technique of operation is merely a simplified version of the operation of the complete unit, which is fully described in the following section on procedures.

(c) The Experimental Unit.-A photograph of the experimental unit (fig. 13) and the distillation train of this apparatus (fig. 14) are reproduced. This assembly included other types of distillation tubes, adsorption tubes, vapor-pressure manometers, etc., which are not described in the present paper.

These photographs illustrate the type of mounting recommended. The basic mounting is an iron frame constructed from $1 / 2$-inch steel rods spaced 4 inches apart and firmly anchored with angle braces at the back and flanges at the bottom. Ordinary $V$ type clamp holders are used to secure the apparatus supports. These supports consist of cups cast in graduated sizes, into which bulbs and heavier parts are set in plaster of Paris. Tubes are secured with small clamps also cast in graduated sizes. The glass tube is wrapped with ordinary $1 / 2$-inch adhesive tape before the clamp is applied. Such clamps occupy little space.

This type of mounting has three distinct advantages. When properly assembled, no strains are left in the glass connections, and expansion joints are unnecessary; a wooden support is likely to warp 
and so develop strains in fused glass joints. The whole apparatus is easily accessible to the glass-blower's torch. When a wooden mounting is used this is not invariably the case, and even when openings are provided in a wooden backing a distressing amount of destructive distillation of wood is apt to occur when repairs to the glass parts become necessary. The apparatus can be easily and quickly changed to suit experimental developments or special needs. If other advantages were lacking, this one alone would justify the use of the mounting here described.

\section{GENERAL PROCEDURES}

When general procedures are explained, direct reference will be made to the assembly diagram. (Fig. 10.) As previously noted, corresponding parts of other line drawings and photographs have been identically lettered.

\section{PREPARATION OF APPARATUS FOR A DETERMINATION}

To prepare the apparatus for a determination, the mercury and gas reservoirs ( $R$ series), burettes (B series), and capillary distributor train (stopcocks 5 to 17 ) are filled with clean mercury.

The entire distillation train ( $I$ to $V$ ), condensation bulbs (C series), connections to pressure gauges ( $\mathrm{M}$ series), and traps $T_{1}$ and $T_{2}$ are evacuated by opening all interconnecting stopcocks and using the mercury vapor pump $\left(V_{1}\right)$ with a mechanical backing pump (vacuum No. 2). During this operation stopcocks 18 and 19 are opened and stopcock 20 is closed. The very small residual pressure left by the mechanical pump in the line between the mercury vapor pump nozzle and stopcocks 18 and 20 may be removed if necessary by closing stopcocks 18 and 19 and opening stopcock 20, which allows the Töpler pump $\left(V_{2}\right)$ to back the mercury vapor pump. Stopcocks 18 and 19 remain closed during a subsequent determination.

The McLeod gauge $\left(M_{2}\right)$ is used to measure the degree of evacuation. When this indicates a pressure of $0.0001 \mathrm{~mm} \mathrm{Hg}$ or less, and the apparatus has been pumped sufficiently long to remove water vapor and gases adhering to the glass walls, ${ }^{16}$ the unit.should be closed. to the pump and allowed to stand overnight in order to detect possible leaks. Tube $I I$ should be immersed in liquid air. If the pressure increase during this interval is no greater than $0.0005 \mathrm{~mm}$, the apparatus may be considered to be in a satisfactory state for the present work, although it is to be preferred that the McLeod gauge indicates no increase of pressure. Leaks may be isolated and detected by closing all interconnecting stopcocks, opening them one at a time, and noting in which section pressure has built up. A high-frequency discharge may then be used to locate the actual point of leakage.

10 This may require as long as 24 hours continuous pumping when the glass parts have not been heated previously. 


\section{ORDER OF PROCEDURE DURING A SINGLE DETERMINATION}

The course taken by a gas sample and the various manipulations to which it is subjected during a single determination may be traced with reference to the assembly diagram. (Fig. 10.) After this is understood the various manipulations may be described in detail.

The sample is introduced at stopcock 11, measured in the burette $B_{2}$ and transferred through the capillary distributor train through stopcock 5 to the mercury trap $M_{1}$ and thence through stopcock 40 to the distillation train $(I I)$. Here it is separated into three fractions by a system of isothermal fractional distillation at low temperatures. The first fraction consists of isobutane plus lower boiling components and is transferred by pumping and condensation from the distillation train through the pumps $V_{1}$ and $V_{2}$ and bulb $C_{6}$, and by direct condensation to bulb $C_{1}$, to the burette $B_{2}$, where its volume is determined. It is then stored in the reservoir $R_{7}$. The second fraction consists of normal butane, which is removed from the distillation train by direct condensation in the bulb $C_{1}$, and thence vaporized into the burette $B_{2}$ and there measured and retained. The third fraction consists of pentane and higher boiling hydrocarbons. Throughout this paper frequent reference will be made to this fraction, which, for the sake of brevity, will be called simply the "pentane fraction." Its liquid volume is determined in the burette $B_{1}$. It is then transferred by condensation to the bulb $C_{2}$ and its vapor pressure determined at a chosen fixed temperature. Measured increments of the butane fraction are condensed from the burette $B_{2}$ in to the mixture contained in the bulb $C_{2}$, and the increase of vapor pressure observed for each increment of butane. The mixture of butane with the pentane fraction may also be measured in the liquid phase with each addition of butane. This completes the operation for a single determination.

\section{MEASUREMENT OF GAS VOLUMES}

The gas burette is connected to the distribution train to permit the sweeping out of a sampling line through stopcocks 11, 10, 27, and 26 in series. The side arm leading from the sampling outlet of stopcock 11 is immersed in mercury and acts as a manometer to indicate proper adjustment of pressure during the transfer of the sample. This is quite convenient if the sample is taken from a cylinder under pressure. Mercury is drawn into the burette reservoir $R_{3}$ by vacuum (No. 3) and flows back under atmospheric pressure.

A sample of 1 to 2 liters should be taken. The bulbed burette recommended is capable of determining the volume of the whole or any fraction by a single measurement and saves considerable time over an instrument of smaller capacity. The fractions and the original sample are measured against the same compensator pressure 
and for convenience are usually measured saturated with water vapor. Since the distilled fractions emerge quite dry, care must be taken to insure their saturation in the burette.

It is necessary to calibrate the condensation bulb $C_{1}$ so that its volume and that of the connections from stopcock 28 to stopcock 25 are known. This volume is then added to the burette reading when gas has been transferred for measurement through the medium of condensation in $C_{1}$ and subsequent vaporization into $B_{2}$.

Reference to the detailed operation of the burette of Figure 1 has already been made. ${ }^{17}$ An ordinary gas analysis burette may be used, but is not as satisfactory with respect to accuracy, speed, and convenience.

\section{TRANSFER OF GAS VOLUMES}

The initial evacuation of the apparatus has been described. Subsequent transfer of gas volumes is done by the pumps $V_{1}$ and $V_{2}$ acting in series and by the method of alternate condensations and vaporizations.

The first fraction resulting from the distillation is transferred by both of the above methods. The nitrogen and a portion of the methane are pumped from the distillation train through stopcocks 1 and 2 , adjusted to by-pass the $P_{2} O_{5}$ drier, and thence through the mercury vapor and Töpler pumps to the reservoir 12. This gas is then transferred by mercury displacement to reservoir 11 and thence to the burette $B_{2}$. During this pumping the major portion of the methane pumped by $V_{1}$ has been collected in the bulb $C_{6}$ by condensation at $-210^{\circ} \mathrm{C}$. Since its vapor pressure is less than $1 \mathrm{~mm}$ of mercury at this temperature, the mass of the vapor over the solid is very small. Stopcocks 20 and 22 are closed, and the methane condensate is vaporized through stopcocks $21,23,16-10$, and 27 into the burette. The residual gas in the bulb $C_{6}$ is removed by the Töpler pump and transferred to the burette. The greater portion of the methane in the original sample is condensed in tube $V$ at $-210^{\circ} \mathrm{C}$., and this, together with the ethane, propane, and isobutane which are separated in a following step, is removed from tube $V$ by vaporization therein and condensation at liquid air temperatures in the bulb $C_{1}$. This condensate is in turn vaporized into the burette, and the total volume of the isobutane and lower boiling components is determined at one measurement. It is then transferred by mercury displacement to the reservoir $R_{7}$, stopcock 3 being opened to the atmosphere and stopcock 4 to vacuum No. 3 for this purpose.

The other fractions are transferred directly by condensation at liquid air temperatures to the desired bulbs. Bulbs $C_{3}, C_{4}$, and $C_{5}$, may be used for the storage of fractions in the liquid phase. 
Since methane possesses a vapor pressure of approximately only $1 \mathrm{~mm} \mathrm{Hg}$ at $-210^{\circ} \mathrm{C}$, and the vapor pressures of ethane or higher boiling components are negligible at ordinary liquid air temperatures, the presence of nitrogen alone makes necessary the complication of a mercury pump. As it is, a great deal of time is saved by using the mercury pump to remove the nitrogen only.

\section{OPERATION OF THE DISTILIATION TRAIN}

The gas sample enters the evacuated distillation train through the mercury trap $T_{1}$. This is designed to permit the draining of the entrapped mercury while the distillation train is under reduced pressure, an operation performed by opening stopcock 37 to vacuum line No. 3, draining through stopcock 38 , and subsequently draining through stopcock 39 with stopcock 38 closed and stopcock 37 turned to the atmosphere.

The pressures within the distillation train are read by the barometric manometers $M_{1}, M_{3}, M_{4}$, and $M_{5}$ and the McLeod gauge $M_{2}$. The latter compression manometer is connected to the train through a $120^{\circ}$ stopcock (42), which permits the reading of pressures in tubes $I I$ and III independently. A second gauge so connected to tubes IV and $V$ is very helpful during more involved separations.

Stopcocks $43,45,47$, and 49 , with outlets leading through ordinary rubber stoppers, may be connected to either air or vacuum line No. 1. This vacuum provides a means of boiling liquid air under reduced pressure. The mouth of the Dewar tube containing the liquid air may be made to seat satisfactorily around the rubber stopper when vacuum is applied, if care is taken to dry the tapered sides of the stopper. This simple device works quite as well as the ordinarily used large rubber tube surrounding the outside of both stopper and Dewar tube, since the applied vacuum strongly seats the stopper.

When the sample is first transferred from the burette, stopcocks $31,40,41,42,44,46,48,50,51,52,57,28,1,18,19$, and 21 should all be closed. Tubes $I I, I I I$, and $I V$ are surrounded with liquid air and tube $V$ and bulb $C_{6}$ with liquid air boiling under reduced pressure (approximately $20 \mathrm{~mm}$ ).

Stopcock 40 is opened to slowly admit the sample to tube $I I$. The condensation which takes place should not be too rapid and may be gauged by the boiling of the liquid air surrounding this tube. If the sample contains little nitrogen, it will be possible to transfer all of it into tube $I I$. If the partial pressure of the nitrogen is sufficiently high, the pressure will build up to exceed atmospheric. When this condition is indicated by the barometric manometer $M_{1}$, stopcock 40 is closed and stopcock 44 carefully opened until the manometers $M_{1}$ and $M_{3}$ indicate equal pressures. Stopcock 44 is then closed and 40 again opened, the operation being repeated, and possibly extended 
to tubes $I V$ and $V$, until the total sample has been transferred from the burette and followed by a displacing column of mercury through the distribution train and into the trap $T_{1}$.

When the sample has been completely transferred, its actual separation is started. The detailed description of this process will follow. (Sec. VI.) The general operating procedure is given in the following paragraphs.

The method of separation depends upon the presence of condensable gases only, since the courses of all distillations are followed directly by observing relevant vapor pressures, and the distillates themselves are transferred entirely by condensation. The first step of the separation is therefore the removal of nitrogen, which does not condense at the lowest temperature employed. This is accomplished by pumping from the distillation tubes as described in Section VI.

When the nitrogen is removed, the hydrocarbons are separated by a system of isothermal distillation. The fraction to be separated is held at a constant temperature in one of the distilling tubes, or, if the rectifying tube $(I)$ is used, a uniform temperature gradient is held over the length of the column. The distilling temperature is determined from a study of the vapor pressures of the pure components and should be chosen so that the component to be distilled possesses an appreciable vapor pressure while the component of next higher boiling point has a practically negligible vapor pressure. With the distilling tube held at such a temperature, the next tube in the series is surrounded with a bath, the temperature of which is sufficiently low to lower to a negligible figure the vapor pressure of the component to be distilled over. When the two tubes are then connected through the intermediate stopcock, the low boiling component vaporizes at the higher distilling temperature and liquefies at the lower condensing temperature. The operation required in a single distillation is then simply the adjustment of these two temperatures and the turning of a stopcock.

Since, in the course of a single distillation, some of a higher boiling component may distill over with the low boiling one, the distillate is partially vaporized and recondensed at the temperature selected for the next distillation. A second distillation is then made, the distillate being collected as before by condensation in the next tube in the series and the residue transferred back to the first tube. In this manner the distillates move progressively forward and the residues backward with each distillation. The system then requires a minimum of three distilling tubes, but as many more may be added as the operator wishes. The additional tubes permit conducting two or more separate distillations at one time, which is a great time saver. Five is probably as many as will be convenient in most cases. 
The course of a single distillation is followed entirely by observing: the vapor pressures. A tube is adjusted to the proper temperature for a distillation, and the vapor pressure of the contained mixture is observed. When the distilling tube is connected to the condensing tube, this pressure drops to some intermediate value and from this gradually diminishes to become equal to or less than the saturation pressure of the low boiling component in its pure state, measured at the condensing temperature. This provides a first basis for judging: the completion of a distillation.

If, during the course of a distillation, the stopcock is closed between the distilling and condensing tubes, the pressure in the distilling tube will gradually approach the originally observed vapor pressure if the low-boiling component is present. On the other hand, it will not change if this component has been removed. This provides a second basis for determining the completion of the distillation.

If the distilling tube then remains shut off from the condensing tube and the residue contained in the distilling tube is totally or partially vaporized at room temperature and subsequently cooled to the same distilling temperature as before, an increase over the vapor pressure observed just before this vaporization indicates the presence of further traces of the low-boiling component.

If the distillate from a first distillation is redistilled, the resulting third distillate may have a higher vapor pressure than the previously observed pressure of the second distillate, measured at the same distilling temperature, and so indicate the presence of a higher-boiling component in the second distillate. A further comparison of the saturation pressures of this third and a fourth distillate, and so on, until they become equal, will finally establish the fact that the higherboiling component has been removed.

If a fraction be distilled so that a small initial distillate and a small final residue may be condensed at an identical temperature (surrounded by the same well-stirred bath) and their vapor pressures measured simultaneously, either by two of the manometers of the apparatus or by a differential manometer, the purity of the fraction so tested may be established or disproved. This test is quite severe. It will be discussed in detail in part 7 of this section. From such simple vapor-pressure observations as these, the proper course of a distillation may be determined and its progress followed.

In performing a separation it is unnecessary to determine accurately the vapor volumes of each distillate and residue; but the vapor volumes of the residues and distillates obtained toward the end of the separation of any component indicate the completeness of this separation. The volumes are usually very small, and their relative order of magnitude may be determined by simply reading the pressures on various barometric manometers when the distilling tubes are at room 
temperature. These small final volumes form a still further means of determining the progress of a distillation, but they alone are very misleading, since it is possible to collect a distillate almost indefinitely, though very slowly, long after the desired component is removed. A new operator has a tendency to do this very thing and therefore should give careful consideration to the discussion of vapor pressure observations.

The vapor pressures of the hydrocarbons at very low temperatures are not accurately known, although their orders of magnitude are well established and reasonably good approximations can be computed. These data would be quite helpful in following the course of a distillation, but they are not entirely necessary and serve only as rough guides. This is obviously true when the lowering of vapor pressure by higher boiling impurities is considered. It would not be logical-for example, in distilling propane from a mixture of butane and pentane-to consider the propane removed from the higher boiling components when the vapor pressure of the residue had been lowered to that of butane at the particular distilling temperature employed. It would be necessary to continue the distillation until the vapor pressure of the residue is somewhat lower. For this reason the exact adjustment of distillation temperature is not important, except when comparative vapor pressure readings are to be taken.

From a consideration of the foregoing paragraph it is apparent that a distillation is more readily followed if only two components are present. This should usually be approached as nearly as possible in actual practice. For example, if propane is to be separated from butane and heavier hydrocarbons, it may be of advantage to make an initial cut which will include all of the propane with a great deal of butane and possible traces of pentane and proceed to separate the propane from this mixture rather than from the total residue. The decision as to the worth of this step is made entirely on the basis of the composition of the original gas. If the partial pressures of propane and higher boiling components are apparently relatively high, the step will save time.

\section{MEASUREMENT OF VAPOR PRESSURES}

A true equilibrium between liquid and vapor phases is somewhat difficult to achieve and maintain. Since the rapid attainment of true equilibrium requires stirring, the vapor pressures measured in the distilling tubes are not likely to be quite correct; but because of the small volumes used and the relatively large surface of liquid exposed they should be very near the correct values. Care must be taken to see that some condensate is present, so that a saturation pressure and not a fixed gas pressure is measured. The precaution is mentioned since the case often obtains where very small volumes of liquid exist. If the pressure is low within the distillation tube, it is necessary to 
allow 10 to 12 minutes for proper adjustment of temperature equilibrium between the copper block and the interior of the distillation tube.

When the manometer $M_{6}$ is used, the condensate may be very simply stirred by vibrating the long, thin stem of the bulb $C_{2}$. This method may appear crude; yet it not only produces very satisfactory mixing, but it is the only practical means because of the very small liquid volumes resulting from a 1-liter sample. An electro-magnetic stirring device within the bulb is impractical in this instance.

The arm of the manometer $M_{6}$ adjacent to the condensing bulb should be maintained at the same temperature as the bulb itself if vapor pressures of pentane and heavier hydrocarbons are to be measured above room temperature. If this is not done, distillation from the bulb and condensation in the manometer arm will occur, with resultant error in the observed saturation pressure.

When the manometer $M_{6}$ is used for the measurement of the vapor pressures of the pentane fraction and mixtures of this fraction with butane, a special precaution is necessary. The relevant pressure to be observed in this instance is the vapor pressure of the mixture when the liquid phase is in equilibrium with an infinitesimal amount of the vapor phase. The maximum vapor pressure (for the given mixture at any fixed temperature) is thus attained. It is possible to obtain this pressure by extrapolation of pressure measurements made at various volume ratios of liquid and vapor phase, but it is not necessary to go to this extent in the present work. The required theoretical equilibrium is nearly obtained in practice by reducing the volume of the vapor phase by means of capillary connections between the bulb containing the liquid and the manometer and by measuring the pressure with the mercury meniscus adjacent to the condensing bulb at an etch mark placed at the top of the manometer arm. The manometer arms should be constructed of matched tubing of capillary bore $(2 \mathrm{~mm})$. The bulb should be nearly filled with condensate. Under such conditions the volume of the vapor phase is practically negligible as compared with the total volume of the material in the vapor phase.

\section{DETERMINATION OF PURITIES OF THE DISTILLATES}

The manometer $M_{6}$ may be used for determining the purity of a fraction by a partial isothermal condensation. This is the method ordinarily employed as a criterion of purity, and references to it may be found in the work of Onnes and others. Equations for the quantitative determination of impurities present in a nearly pure substance, depending upon behavior during an isothermal condensation or vaporization, have recently been computed by E. W. Washburn. ${ }^{18}$

18 E. W. Washburn, Zeit. Phys. Chem. (Cohen-Festband), p. 592; 1927. 
The differential manometer provides a somewhat simpler method for testing the purity of a distillate. This eliminates the necessity of a carefully controlled temperature during the progress of an isothermal condensation and at the same time is a more severe criterion of purity. The manometer previously described (Sec. IV, 7 and fig. 8) is used. A distillate whose purity is to be tested is separated by a final distillation into (1) a small initial distillate which is condensed in $B_{2}$ of the manometer, (2) a large middle fraction which is condensed for storage in bulb $C_{3}$ of the train, and (3) a small final residue which is condensed in $B_{1}$ of the manometer. The vapor pressures of the initial distillate and final residue are then directly compared, $B_{1}$ and $B_{2}$ being immersed in the same bath. To insure uniformity of temperature within $B_{1}$ and $B_{2}$, mercury is frozen about them. The temperature selected should be such that the pure substance in question will have an appreciable vapor pressure (5 to $15 \mathrm{~mm}$ of mercury).

If a quantitative estimate of purity is desired, the vapor pressure of a small initial distillate should be compared with that of the entire remaining fraction, and the equations of Washburn ${ }^{19}$ applied. It is evident that in extended work of this nature it would be desirable to prepare a set of manometers each containing one of the hydrocarbons carefully purified. The purity of any distillate could be determined quickly by the use of such a reference set.

\section{SEPARATION OF GAS SAMPLE BY FRACTIONAL DISTILLATION}

\section{ISORDTANE, PROPANE, AND LOWER BOILING COMPONENTS}

This fraction consists of nitrogen, methane, ethane, propane, and isobutane, together with traces of oxygen, carbon dioxide, the rare gases, and the lower boiling unsaturated compounds, if present. Oxyg'en, tog'ether with any rare gases, is separated with the nitrogen; and carbon dioxide, ethylene, propylene, and some of the butylene, if present, are included in the same fraction as the distillation proceeds. Oxygen and carbon dioxide usually occur in traces, although some natural gases contain appreciable amounts of the latter, in which case it should be removed by absorption in sodium or potassium hydroxide before the distillation. The unsaturated compounds are usually not present, and isobutane occurs only in relatively small amounts.

As previously shown, the nitrogen should be removed before the distillation proper is begun. This step would be simple enough were it not for the appreciable solubility of nitrogen in the hydrocarbons at low temperatures. It has not been found feasible to begin this step directly at a temperature suitable for the separation of propane 
from butane because of the danger of carrying over the higher boiling components. Hence, tubes $I I, I I I$, and $I V$ are maintained at liquid air temperatures and tube $V$ at $-210^{\circ} \mathrm{C}$. The sample is transferred to the distillation train, and stopcock 1 is then slowly opened to connect the distilling train to the mercury vapor pump, condensation bulb $C_{6}$ at $-210^{\circ} \mathrm{C}$, , and the Töpler pump in series. When the pressure indicated by the manometer $M_{4}$ has been lowered to approximately $1 \mathrm{~mm}$, stopcocks 48,46 , and 44 are closed, the pump remaining connected to tube $V$. This step accomplishes the removal of the bulk of the nitrogen.

It is now necessary to remove traces of nitrogen left in solution, and at the same time desirable to distill off the methane and the major portion of the ethane. The residue left will then consist principally of propane and heavier components, and the separation of propane and isobutane may be more easily followed without the confusion of the comparatively high vapor pressure readings of ethane and methane at the higher temperatures employed for the propane separation. This step is accomplished as follows: The liquid air bath is removed from tube $I I$ and the residue therein allowed to vaporize until the manometer $M_{1}$ registers slightly under atmospheric pressure. A copper temperature control block previously cooled to approximately $-160^{\circ} \mathrm{C}$. is quickly placed around $I I$, and time allowed for proper adjustment of temperature equilibrium. The stopcocks 44, 46, and 48 are again slowly opened in order. When the pressure in the distillation train has dropped to $1 \mathrm{~mm}$, the nitrogen has usually been completely removed from the residue in $I I$, but traces of nitrogen may still remain in solution in the condensate in $V$. This condensate will contain methane and ethane, with possibly some traces of propane, depending on the composition of the original sample. Stopcocks 4,8 , and 1 are closed, and this fraction is vaporized from $V$ and condensed in $C_{1}$ for transference to the burette. Stopcock 29 is then closed and stopcock 1 opened to pump the residual vapor from $V$. When $M_{5}$ indicates no pressure, stopcock 1 is again closed, and the condensate in $C_{6}$ vaporized to the burette as described in Section $V, 4$.

The residue in $I I$ will contain traces of ethane and rarely methane, together with the major portion of the propane and all isobutane and higher boiling components. The separation of this fraction is usually best done by making an initial distillation at a higher temperature than would be used normally. This will result in distilling over some normal butane or even traces of pentane but leaves a residue free from propane and isobutane. In the case of a "dry" gas (one containing small amounts of the higher boiling hydrocarbons), the separation may be made in tubes $I I-V$, but time is ordinarily saved by using the rectifying tube $I$. One distillation made in tube $I$ has accomplished the same degree of separation as 6 to 10 made in the ordinary tubes. 
In the case of "wet" gases (containing large amounts of higher boiling hydrocarbons), this is particularly noticed.

The residue in $I I$ is accordingly transferred to the distilling tube $I$. The temperature gradient of $I$ is adjusted to the range $-80^{\circ} \mathrm{C}$. at the bottom to $-110^{\circ} \mathrm{C}$. at the top, and $I$ is then opened through $I I$ to III, the latter tube being cooled to liquid air temperature. If the original sample contains relatively high partial pressures of propane and higher boiling components, it may be necessary to cool III to $-210^{\circ} \mathrm{C}$. to condense possible traces of methane which has been held in solution, although this step is usually unnecessary. The distillation from $I$ to $I I I$ is allowed to proceed until the McLeod gauge $M_{2}$ indicates a pressure of approximately $0.3 \mathrm{~mm}$ with stopcock 44 closed and 42 opened to $I I$. The distillate in $I I I$ is then vaporized and recondensed at $-120^{\circ} \mathrm{C}$. A distillation of this mixture is now made, the resulting distillate being collected in $I V$ by condensation at liquid air temperature. This distillation is halted when the McLeod gauge, now connected through stopcock 42 to $I I I$, registers a pressure of 0.2 to $0.3 \mathrm{~mm}$ with stopcock 46 closed (that is, the vapor pressure of the residue is measured). This residue may still contain isobutane and traces of propane, and the new distillate may contain some butane. Accordingly, a further distillation is made from $I V$ at $-120^{\circ} \mathrm{C}$. to $\mathrm{V}$ at liquid air temperature, and the residue from this is transferred to $I I I$, where the combined residues are again distilled at $-120^{\circ} \mathrm{C}$. to continue the separation of isobutane and possible traces of propane. This procedure is continued until the final distillates show no further increase in vapor pressure and the vapor pressures of the final residues indicate no isobutane present. It should be noted that while no great harm will result in carrying over some butane with the final fraction, no isobutane or traces of propane must be left in the residue, since these components would later cause considerable error if included in the normal butane fraction.

It is impossible to state how many such distillations will be required to complete the separation. A "dry" gas will naturally require fewer than a "wet" gas. The fractionation charts which follow illustrate typical examples. The operator should not make the mistake of following these charts step by step, since every natural gas is a separate problem and may require more or less fractionation than the charts illustrate. The charts given are merely examples showing the general trend of such separations.

When the separation of the propane fraction has been completed, the vapor volume of the distillate is determined, after which it may be stored for further check in the reservoirs $R_{7-9}$, or discarded. 


\section{BUTANE FRACTION}

The final residue from the above distillation is transferred to distilling tube $I$, and an initial separation is made with a temperature gradient of -60 to $-90^{\circ} \mathrm{C}$. over the column. The distillate, which is collected at liquid air temperature in tube III, will contain practically all of the normal butane and some pentane. It is accordingly distilled from $I I I$ at a temperature of $-100^{\circ} \mathrm{C}$. into $I V$ at liquid air temperature and the residue returned to $I$, where a second separation is made with a temperature gradient of $-70^{\circ}$ to $-100^{\circ}$. This distillate is collected in III and again separated at $-100^{\circ}$, the new distillate being combined with the former contained in $I V$. A distillation from $I V$ to $V$ may result in further separation, in which case the residue is returned to $I I$. The residue in $I$ is combined with this, and a distillation from $I I$ to $I I I$ is carefully conducted to ascertain if traces of butane still remain in the pentane fraction. If butane is detected in this distillate, a double distillation from III to $I V$ and $I V$ to $V$ is necessary to free it from pentane carried over with the initial distillation from $I I$ to $I I I$. In the case of a gas containing a large proportion of butane and heavier hydrocarbons-as, for example, accumulator condensates, higher boiling fractions from stills or rectifying columns, etc.- the separation is tedious. If the operator has to deal with a large number of such samples, a series of distilling tubes of the rectifying type (tube $I$ ) are recommended.

\section{PENTANE AND HIGHER BOILING COMPONENTS}

This fraction remains as a residue from the previous separations and for the present purpose need not be further separated, since all of its components fall naturally into the classification "natural gasoline." If the separation of this residue is desired for any especial reason, it is best done in a rectifying column similar to that shown in Figure 6. For consistent analytical results a much longer column and a large volume of such a residue are essential. A small rectifying column equipped with bubbling cap plates and reflux drains is to be preferred. Such separations are out of the scope of the present work. •

\section{FRACTIONATION CHARTS}

(a) Types of Gases Separated.-The fractionation charts (figs. 15 to 21) which follow illustrate the steps necessary for the separation of several types of natural gases. The separations have been carried out in more detail than will generally be necessary for a determination of natural gasoline, but this detail will serve to instruct the beginner who may have difficulty in determining the proper end points of the individual fractionations, as well as the actual plans of attack. Separations carried to the extent of those indicated on the fraction- 
ation charts usually result in analyses checking within 0.01 to 0.02 per cent, an accuracy slightly higher than that usually required for a determination of natural gasoline.

Fractionation chart No. 1 illustrates the separation of a natural gas containing 91.79 per cent $\mathrm{N}_{2}+\mathrm{CH}_{4}+\mathrm{C}_{2} \mathrm{H}_{6}, 5.97$ per cent $\mathrm{C}_{3} \mathrm{H}_{8}, 1.45$ per cent $\mathrm{C}_{4} \mathrm{H}_{10}$, and 0.79 per cent $\mathrm{C}_{5} \mathrm{H}_{12}+$ higher boiling $\mathrm{C}_{n} \mathrm{H}_{2 \mathrm{n}+2}$. The sample was taken at an Oklahoma extraction plant.

Fractionation chart No. 2 illustrates the separation of a Pennsylvania natural gas taken at the inlet of a natural gasoline adsorption plant. Chart No. 3 shows the separation of this same gas by use of the rectifying type distillation tube, while chart No. 4 illustrates the separation of the outlet gas from the same plant. The composition of the inlet gas was 96.22 per cent $\mathrm{N}_{2}+\mathrm{CH}_{4}+\mathrm{C}_{2} \mathrm{H}_{6}+\mathrm{C}_{3} \mathrm{H}_{8}, 2.28$ per cent $\mathrm{C}_{4} \mathrm{H}_{10}$ and 1.50 per cent $\mathrm{C}_{5} \mathrm{H}_{12}+$ higher boiling $\mathrm{C}_{\mathrm{n}} \mathrm{H}_{2 \mathrm{n}+2}$, while the outlet gas contained 97.9 per cent $\mathrm{N}_{2}+\mathrm{CH}_{4}+\mathrm{C}_{2} \mathrm{H}_{6}+\mathrm{C}_{3} \mathrm{H}_{8}, 1.85$ per cent $\mathrm{C}_{4} \mathrm{H}_{10}$, and 0.15 per cent $\mathrm{C}_{5} \mathrm{H}_{12}$ + higher boiling $\mathrm{C}_{2} \mathrm{H}_{2 \mathrm{n}+2}$.

Fractionation chart No. 5 illustrates the separation of a Wyoming natural gas containing large amounts of the heavier hydrocarbons: 74.20 per cent $\mathrm{N}_{2}+\mathrm{CH}_{4}+\mathrm{C}_{2} \mathrm{H}_{6}, 19.20$ per cent $\mathrm{C}_{3} \mathrm{H}_{8}, 4.41$ per cent $\mathrm{C}_{4} \mathrm{H}_{10}$, and 3.19 per cent $\mathrm{C}_{5} \mathrm{H}_{12}$ thigher boiling $\mathrm{C}_{\mathrm{n}} \mathrm{H}_{2 \mathrm{n}+2}$. The fractionation of this gas is quite different from that of the "drier" gases preceding.

Chart No. 6 shows the separation of a commercial propane and illustrates in a general way what can be done with special still samples.

Chart No. 7 illustrates the separation of the nitrogen-methane fraction and the ethane fraction from a "wet" natural gas and is included for reference by those who wish to determine the entire composition of a natural gas as well as its natural gasoline content.

(b) Key to Interpretation of Fractionation Charts.-The various steps of the fractionation have been abbreviated on the charts because of the small space allowed for presentation.

The Roman numerals represent the distilling tubes as they occur on the assembly diagram. (Fig. 10.)

The data expressed to the right of each Roman numeral are arranged - in the following order:

1. Kind of procedure.

2. Temperature in $-{ }^{\circ} \mathrm{C}$.

3. Pressure in $\mathrm{mm} \mathrm{Hg}$.

The kind of procedure is abbreviated thus:

$c$, indicates a condensation.

$v$, indicates a vaporization.

$d$, indicates a distillation.

$t r$, indicates a transfer without distillation.

When the directional lines of a chart lead to the symbols $V_{1} V_{2} C_{6}$, the gas has been pumped by the mercury vapor pump $\left(\nabla_{1}\right)$ and 
automatic Töpler pump $\left(V_{2}\right)$ and condensed in the bulb $\left(C_{6}\right)$, from which it is transferred to the burette $\left(B_{2}\right)$ for measurement. An example may be taken to illustrate.

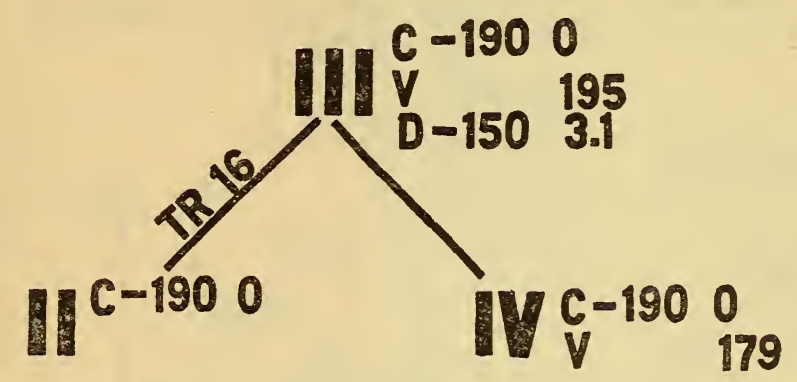

Key to fractionation charts

The interpretation is as follows: A mixture in tube III has been condensed at $-190^{\circ} \mathrm{C}$. to a pressure of $0 \mathrm{~mm}$. It has then been vaporized at an unmeasured temperature (always that of the room) with the resulting gas pressure (not vapor pressure) of $195 \mathrm{~mm}$. It was then distilled at $-150^{\circ} \mathrm{C}$., at which temperature it possessed an initial vapor pressure of $3.1 \mathrm{~mm}$. The distillate was collected in $I V$ at $-190^{\circ} \mathrm{C}$., where it was condensed to a pressure $0 \mathrm{~mm}$. This distillate was vaporized at unmeasured (room) temperature to a pressure of $179 \mathrm{~mm}$. The residue left in $I I I$ was vaporized and transferred to $I I$, where it was condensed at $-190^{\circ} \mathrm{C}$. to $0 \mathrm{~mm}$. Its vaporized pressure was $16 \mathrm{~mm}$.

Note.-The relation $195 \mathrm{~mm}$ (pressure of original mixture when vaporized) $-179 \mathrm{~mm}$ (pressure of vaporized distillate) $=16 \mathrm{~mm}$ (pressure of vaporized residue) will, of course, not hold accurately in the actual apparatus, since the vapor spaces in these tubes are not all identical, and atmospheric temperature does not remain constant.

(c) Discussion of Charts.-Fractionation chart No. 1 (fig. 15).Since the percentage of propane was desired in addition to the natural gasoline content, the analysis was made to include this extra determination. Nitrogen, methane, and ethane were grouped for the first fraction. The first step consisted in merely drawing off the nitrogen, together with most of the methane and some ethane. This was accomplished by pumping from bulbs $I$ to $I V$ in series, all held at $-185^{\circ} \mathrm{C}$. The residues were then transferred back to $I$, and the separation of the remaining ethane from the propane and higher boiling constituents was carried out by a series of distillations at $-150^{\circ} \mathrm{C}$.

It will be noted that the initial vapor pressure of this series was $18 \mathrm{~mm}$ at $-150^{\circ}$, which clearly indicated the incomplete removal of methane at this point. Since the separation may be best followed with reference to the vapor pressures of ethane and propane alone, $47559^{\circ}-29-12$ 
Separation of a natural gas of the composition

\begin{tabular}{|c|c|}
\hline $\begin{array}{r}\mathrm{N}_{2}+\mathrm{CH}_{4}+\mathrm{C}_{2} \mathrm{H}_{6} \\
\mathrm{C}_{3} \mathrm{H}_{8} \\
\mathrm{C}_{4} \mathrm{H}_{10} \\
\mathrm{C}_{5} \mathrm{H}_{12}+\mathrm{Higher} \\
\text { bolling } \mathrm{CNH}_{2 N+2}\end{array}$ & $\begin{array}{l}91.79 \% \\
5.97 \% \\
1.45 \% \\
0.79 \%\end{array}$ \\
\hline
\end{tabular}

Somple $1037.5 \mathrm{cc}$
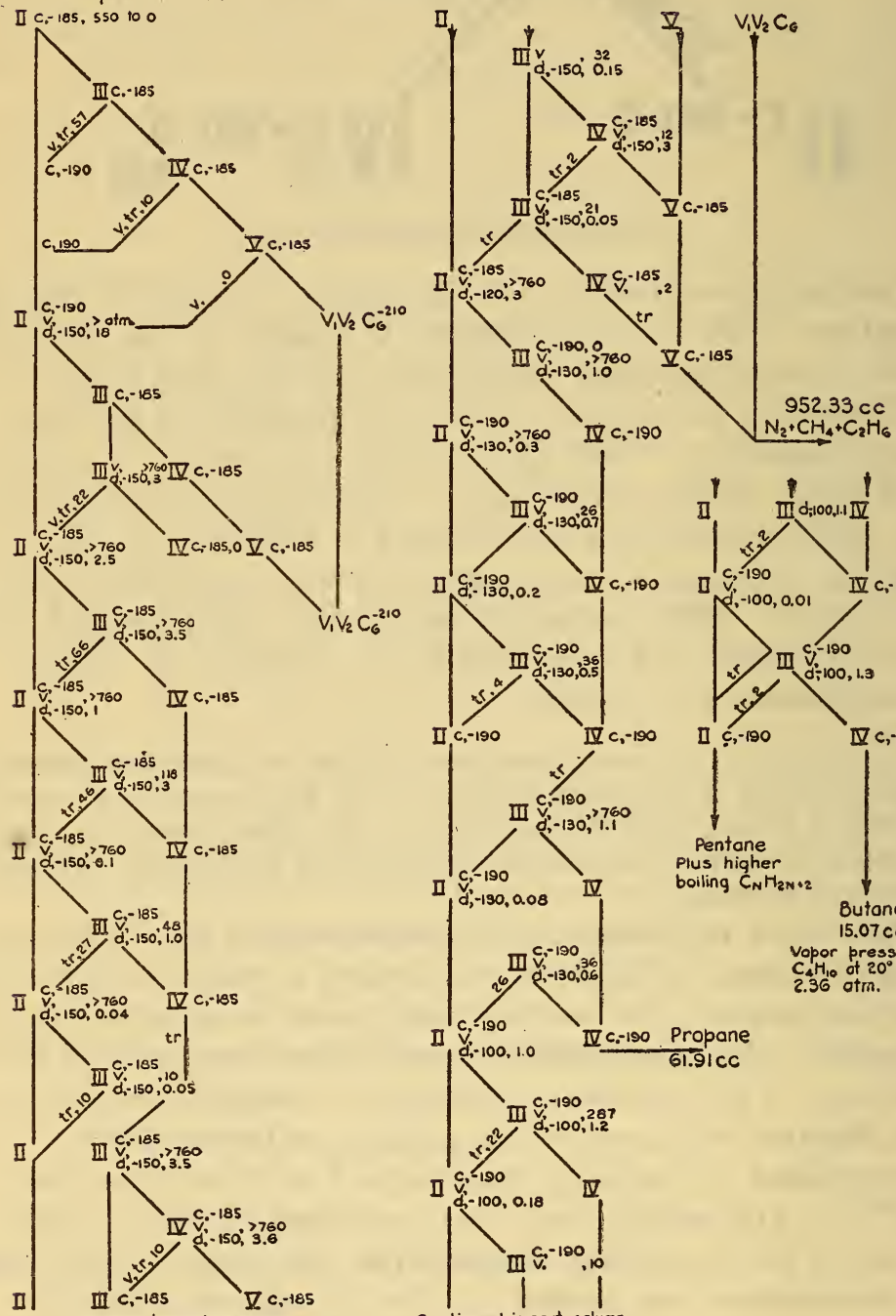

Continued in next column

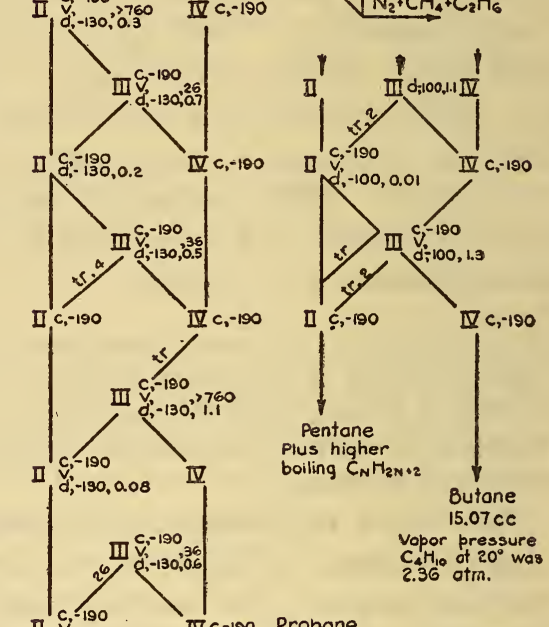

FIgURE 15.-Fractionation chart No. 1 


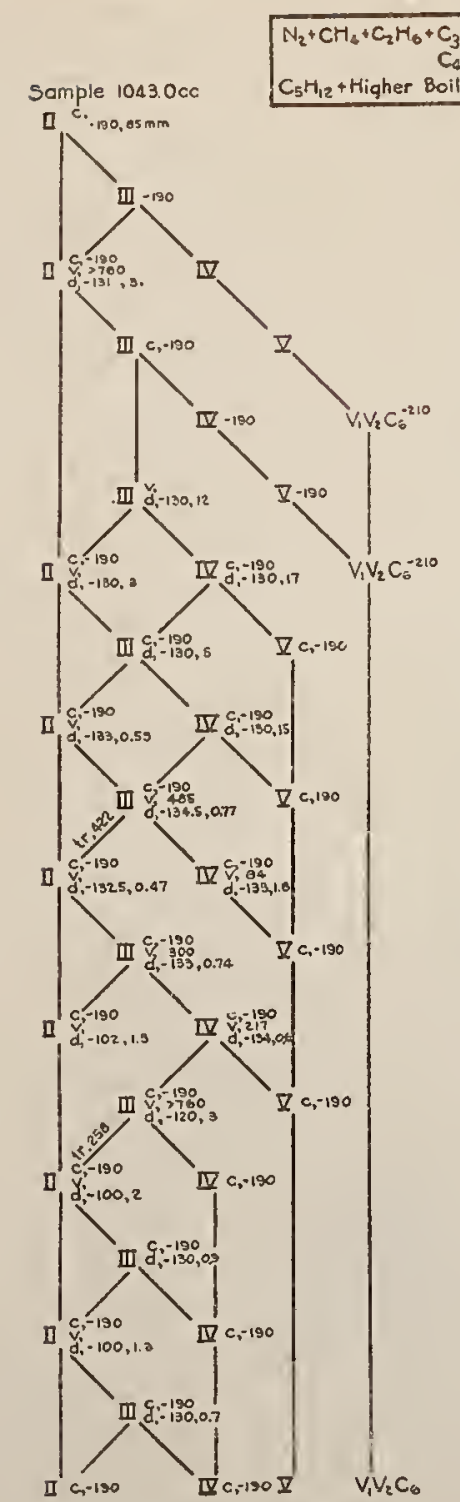

$\begin{array}{rr} & 96.22 \% \\ 3 H_{8} & 2.28 \%\end{array}$

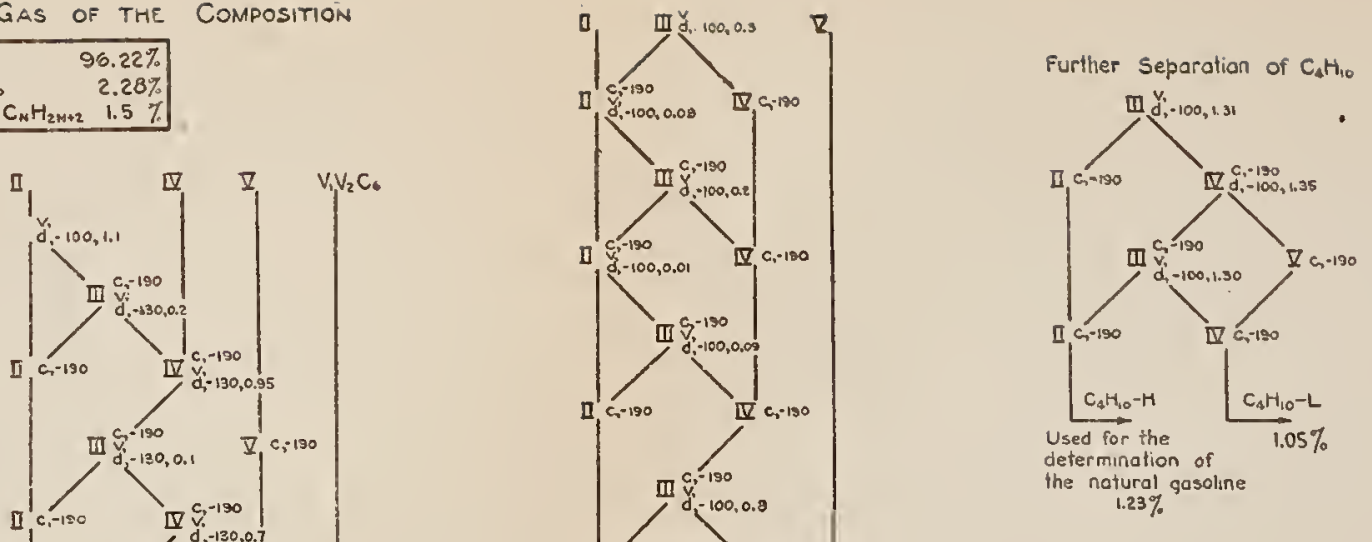


Separation of the same natural gas as chart 2 Using Rectifying Type Distillation Tube

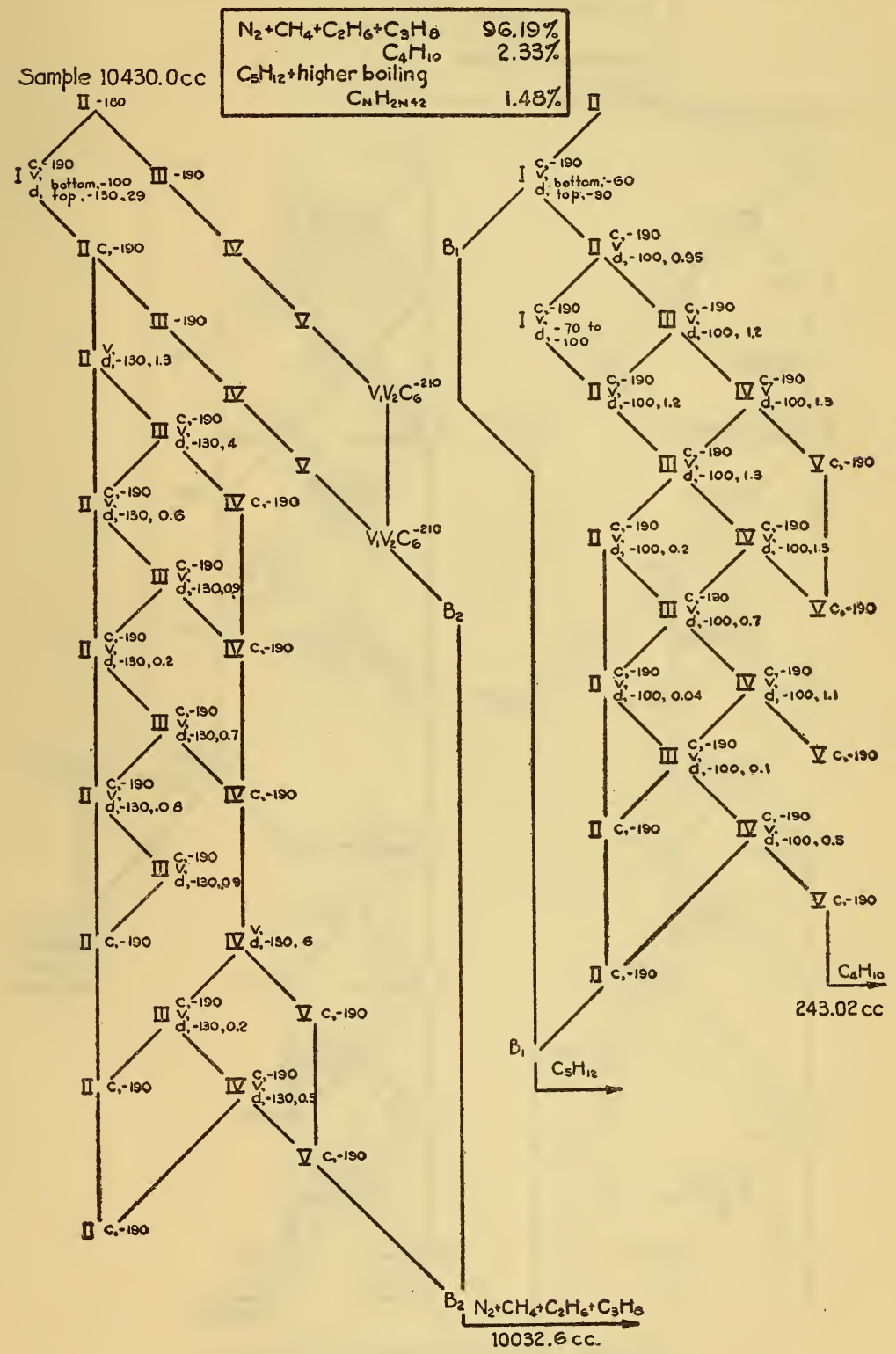

FIGURE 17.-Fractionation chart No. 8 


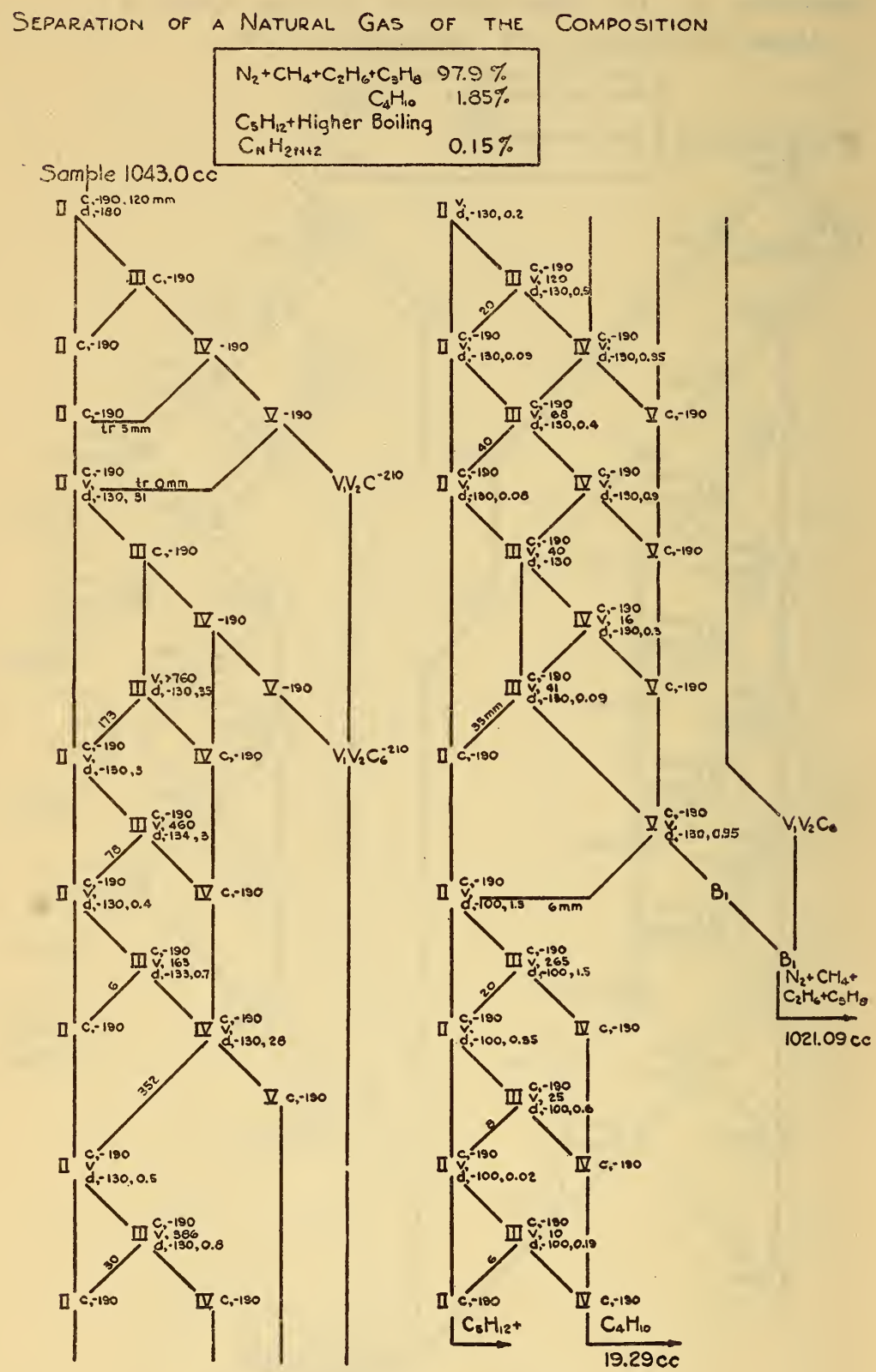

Figdre 18.-Fractionation chart No. 4 
Separation of a gas of the composition

\begin{tabular}{|c|c|c|}
\hline $\mathrm{N}_{2}+\mathrm{CH}_{4}+\mathrm{C}_{2} \mathrm{H}_{6}$ & & $74.20 \%$ \\
\hline $\mathrm{C}_{3} \mathrm{H}_{8}$ & & 19.20 \\
\hline $\mathrm{C}_{\mathrm{a}} \mathrm{H}_{10}$ & & 4.41 \\
\hline $\mathrm{C}_{5} \mathrm{H}_{12}+\mathrm{Higher}$ Bolling & $\mathrm{C}_{N} \mathrm{H}_{2 \mathrm{~N}+2}$ & 3.19 \\
\hline
\end{tabular}
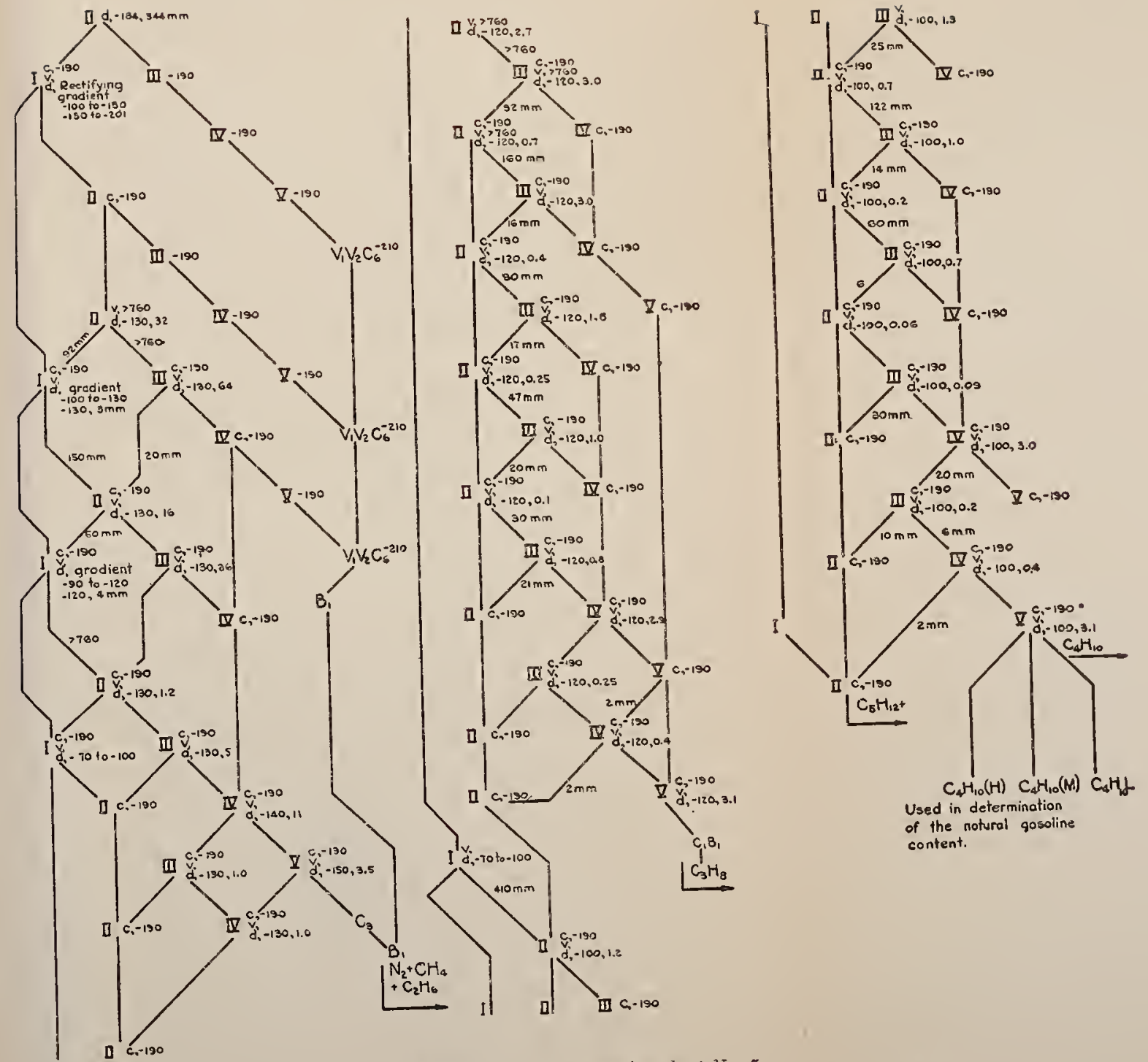

Figure 19.-Fractionation chart No, 5

47559 -29. (Face p. 1179.) 


\section{Separation of a Commercial Propane} Sample $123.73 \mathrm{cc}$.

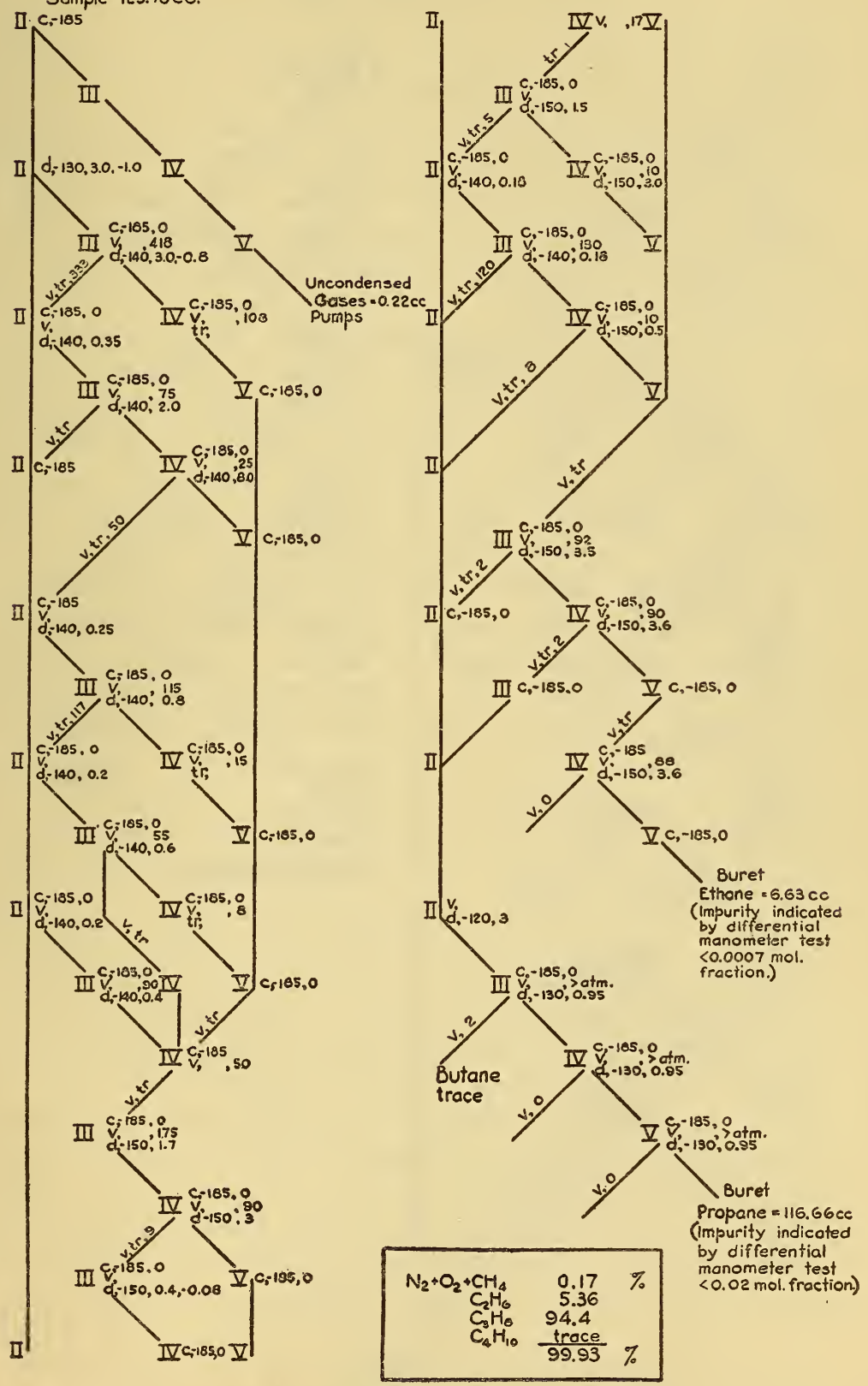

FIgURe 20.-Fractionation chart No. 6 
SEPARATION OF NITROGEN + METHANE AND ETMANE.

From a WeT" natural Gas

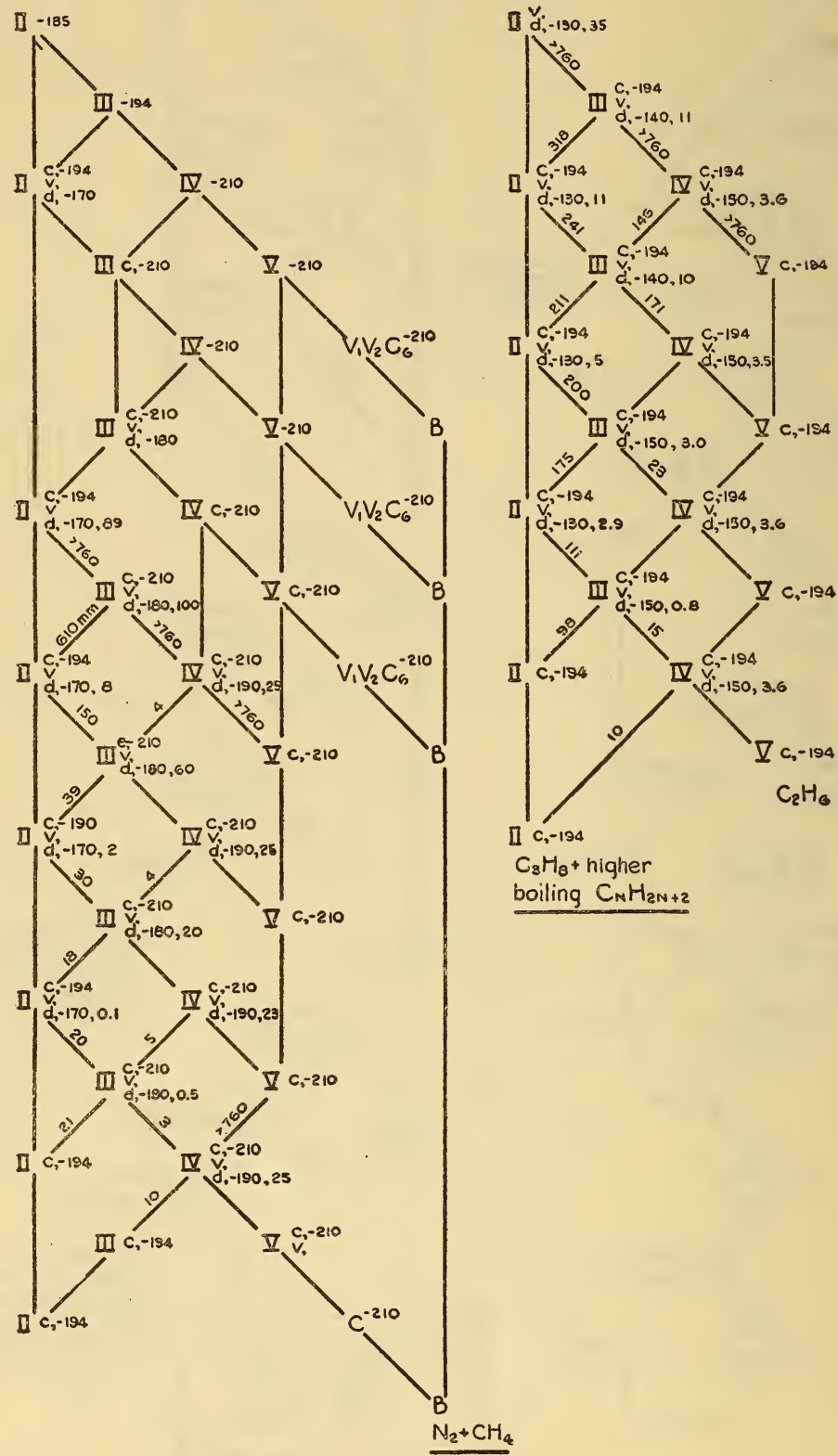

FIGURE 21.-Fractionation chart No. 7 
the methane was pumped off from $I I$ with $I I I$ and $I V$ in series at $-185^{\circ} \mathrm{C}$. The distillation then proceeded normally from $I I$.

The separation of ethane from the propane-plus residue required four cuts from the original mixture at $-150^{\circ} \mathrm{C}$. A better system would have included an initial cut at $-130^{\circ}$ to $-140^{\circ}$, effecting the complete separation of ethane, if possible, followed by distillations at $-150^{\circ}$ to separate the ethane from the appreciable amount of propane carried over with the first distillate. Once the composition is known, it is usually possible to advantageously revise the system of fractionation, so that a check analysis requires less time.

The present chart illustrates how a separation is followed to completion. Having in mind the generalizations laid down in Section $\mathrm{V}$, 5, the course of the separation is easily followed. The initial mixture possessed a vapor pressure of $2.5 \mathrm{~mm}$ at $-150^{\circ} \mathrm{C}$. The vapor pressure of the first distillate was raised to 3.5 at the same temperature, while that of the residue was lowered to 1.0. Similarly, the vapor pressure of the fourth residue in $I$ had diminished to 0.04 $\mathrm{mm}$, and the very. small distillate from this residue possessed the same vapor pressure within $0.01 \mathrm{~mm}$. Evidently the ethane had been completely removed from the residue in $I$. Traces of propane remained in the combined distillates in $I I I$, however, as was evidenced by the slight increase in vapor pressure (3.5 to 3.6) upon a further distillation. Only $10 \mathrm{~mm}$ of the residue remained from the further distillation of the distillate whose initial vapor pressure was $3.6 \mathrm{~mm}$. When this was combined with the previous residue, the total pressure was $32 \mathrm{~mm}$. The vapor pressure of this residue at $-150^{\circ}$ was 0.15 $\mathrm{mm}$, well under the vapor pressure of ethane $(3.6 \mathrm{~mm})$, but over that of propane at the same temperature (approximately 0.05). A distillation of this residue recovered only $12 \mathrm{~mm}$ of distillate, the vapor pressure of which was $3.0 \mathrm{~mm}$ at $-150^{\circ}$-clearly a mixture predominant in ethane but containing some propane. Since the gas volumes here involved were so small, the separation might well have been concluded forthwith. The final step was added simply to show how the residue could be worked back to a vapor pressure of $0.05 \mathrm{~mm}$ at $-150^{\circ}$, from which a further distillation gave no measurable separation. The separations of propane and butane may be followed in a like manner. Since the partial pressures of butane and higher boiling components were low, the separation was carried out in the tubes $I I$ to $I V$ rather than in the rectifying tube $I$. The propane was added to the ethane and lower boiling components and the natural gasoline determined from the butane and pentane-plus fractions.

Fractionation chart No.2 ( fig. 16).- - In the case of this sample the natural gasoline content was desired without reference to the complete composition of the natural gas. Accordingly, the nitrogen, 
methane, and ethane were separated in a double step, which also served to begin the separation of the propane fraction. The propane was first separated from the original mixture by a series of distillations at $-130^{\circ} \mathrm{C}$. It was soon evident that butane and higher boiling hydrocarbons were present in sufficient quantity to materially retard the complete separation of propane. The initial distilling temperature was therefore raised to $-100^{\circ} \mathrm{C}$., followed by second and third distillations at $-130^{\circ} \mathrm{C}$. The combined distillates from the series of third distillations were redistilled to safeguard against butane being carried into the final propane fraction. Thus, at the end of 23 distillations, propane was separated from the residue of higher boiling hydrocarbons and added to the ethane and lower boiling components.

There now remained in the residue a mixture of butane and higher boiling hydrocarbons, which subsequent analysis showed existed in the approximate ratio of $3 \mathrm{C}_{4} \mathrm{H}_{10}: 2 \mathrm{C}_{5} \mathrm{H}_{12}$ plus higher boiling components. This is an average condition which may be expected in many natural gas samples, and it is accordingly interesting to note the fact that the separation of the butane was not accomplished until the twenty-fifth distillation. At this point, however, propane was indicated in the butane fraction. Its presence would necessarily ruin the natural gasoline determination, and it was therefore separated from the butane by seven additional distillations. The butane fraction was then subjected to further separation to exclude possible traces of propane and isobutane which would interfere with the determination of natural gasoline. Three distillations divided the butane fraction into two roughly equal parts, and the higher boiling portion was retained for mixing with the pentane fraction in the ultimate determination of the gasoline.

Fractionation chart No.3 ( fig. 17). - The natural gas of chart No. 2 is evidently a type best separated with the aid of the rectifying tube. This is illustrated by chart No. 3 .

Nitrogen, methane, and most of the ethane were removed exactly as before. The removal of propane from the higher boiling hydrocarbons, however, was accomplished by a single distillation in rectifying tube $I$, a temperature gradient of $-100^{\circ}$ to $-130^{\circ} \mathrm{C}$. being used for this purpose. The butane, carried over with the propane (and some ethane), was removed by a series of 11 distillations in the ordinary tubes $I I$ to $V$. The butane was then separated from the pentane by two separate distillations from the rectifying tube $I$, the temperature gradients of $-60^{\circ}$ to $-90^{\circ} \mathrm{C}$. and $-70^{\circ}$ to $-100^{\circ} \mathrm{C}$. being used. Twelve intermediate and additional distillations from tubes $I I$ to $V$ served to return the pentane carried over with the butane.

Comparison of chart No. 2 with chart No. 3.-A comparison of the two methods used for separating this gas should now be made. 
Nitrogen, methane, and the larger portion of the ethane were removed by the same procedure in both cases.

Propane was removed by 23 distillations from the plain tubes alone, while the initial use of the rectifying tube for one distillation made possible the completion of the separation with only 11 additional distillations from the plain tubes.

The initial distillation of propane from the plain tube did not result in the complete removal of ethane to the pump system, since the vapor pressure of the distillate remained as high as $12 \mathrm{~mm}$ at $-130^{\circ}$ C. for the second distillation. The vapor pressure of the corresponding distillate from the rectifying tube had dropped to 1.3 $\mathrm{mm}$ at the same temperature-about $0.3 \mathrm{~mm}$ above the vapor pressure of pure propane at that temperature.

A comparison of the vapor pressures of the distillates in both cases shows that the rectifying tube not only separated all of the propane from the higher boiling hydrocarbons but at the same time removed a distillate having a smaller boiling range. The vapor pressures of the distillates (in $\mathrm{mm}$ ) in the case of the plain tubes were 12, 17; $3,5,15 ; 0.53,0.771 .8 ; 0.47,0.74,0.6$, etc. The vapor pressures in the case of an initial distillation from the rectifying tube were 1.3 , $4 ; 0.6,0.9 ; 0.2,0.7 ; 0.08,0.09$.

A similar comparison may be made for the butane separations. The plain tube method required 25 distillations to separate the butane from the pentane-plus residue and 7 additional distillations to remove some propane which had not been properly separated from the butane-plus residue. Two distillations from the rectifying tube yielded distillates containing all the butane and not nearly as much of the pentane, since only 12 additional distillations from the plain tubes were required to complete this fractionation.

Altogether, the first analysis required 45 distillations from the plain tubes, while the second required 3 from the rectifying tube and 23 from the plain tubes.

Limited use of the rectifying tube.-The question naturally suggests itself: Why not eliminate the plain tube altogether and carry out all distillations in a rectifying tube? Two considerations prevent such a method of attack. The first is less important but is, nevertheless, a real consideration. The total time required to establish proper temperature equilibrium and conduct the actual distillation thereafter is about four to five times greater when the rectifying tube is used. The case may then occur where no real saving of time is made by use of the rectifier. The main consideration, however, lies in the fact that the efficiency of the rectifying tube depends entirely on the amount of liquid refluxed from the top of the column. This means that the distillate must not only be withdrawn at a slower rate but also that there must be sufficient volume of liquid to reflux. 
Toward the end of a separation the liquid volumes become very small, and the actual rectifying action of the column is almost negligible. It is therefore much better to use the plain tube during this part of the fractionation.

Unfortunately, in the case of a gas not previously examined it is not always apparent when the distillation should be changed from the rectifier to the plain tube. For example, referring to chart 3 , the separation of propane might have been materially expedited by using the rectifying tube a second time instead of making the first distillation from $I I$ at $-130^{\circ}$ C., $1.3 \mathrm{~mm}$. The cause of confusion here was that the vapor pressure of this particular distillate was almost that of pure propane and therefore indicated the presence of very little butane. Subsequent analysis developed the fact that the distillate was actually a mixture of ethane, propane, and butane. The ethane served to raise the vapor pressure just enough to lead to the false conclusion drawn.

The operator, however, is not apt to have the problem of continually examining natural gases from new fields. Rather, he will usually face the problem of analyzing gases of fairly well-known compositions, even when their sources are from various points of a plant cycle. He will then have the opportunity to determine upon the most advantageous method of separation by merely making a few preliminary separations of each type of gas of which the composition is to be determined.

In general, the rectifying tube should be used for "wet" natural gases and special samples, drawn from plant cycles, which contain large amounts of propane, butane, and the higher boiling hydrocarbons. The plain tube may be used for "dry" natural gases, outlet samples from natural gasoline extraction plants, and other mixtures containing small amounts of the heavier hydrocarbons. It should also be used for the final steps in the distillation of all types of gases.

Fractionation chart No. 4 (fig. 18).-This illustrates the separation of the outlet gas from the extraction plant which used the natural gas of charts 2 and 3 as a raw or inlet gas. It may be taken as fairly representative of the fractional separation of the "dry" type of gases. There are no points of especial interest, except to note that the propane separation was more difficult than had been anticipated, indicating the need of the rectifying tube. The butane separation, on the other hand, was quite easily carried out in the plain tubes. This condition is usually reversed for the case of an untreated "dry" natural gas, although the plain tubes are usually satisfactory for both the propane and butane separation.

Fractionation chart No.5 ( fig. 19).-This chart illustrates the separation of a typical "wet" gas and includes the determination of pro- 
pane by itself as well as the usual three cuts made for the determination of natural gasoline. The rectifying tube was used. Two different temperature gradients were employed to remove ethane from the higher boiling hydrocarbons, and they should be particularly noted, since they are much higher than are ordinarily used. These gradients were chosen because of the unusually large proportion of the higher boiling components. The rectifier was again used for the propane and the butane separations. For this type of gas it would be desirable to have at least two rectifying tubes arranged in the order $I_{a} \rightarrow I I \rightarrow I_{b} \rightarrow I I I \rightarrow I V \rightarrow V . \quad I_{b}$ and $I I$ should be connected so that they might be bypassed, permitting the independent connections $I_{a} \rightarrow I I, I_{a} \rightarrow I_{b}, I I \rightarrow I_{b}$ and $I I \rightarrow I I I$. It would thus be possible to conduct two rectifications at once, using tubes $I I$ and $I I I$ as condensers.

Fractionation chart No. 6 (fig. 20).-The separation of a commercial propane is illustrated by this chart. Ordinarily, a sample of approximately 1 liter would have been taken and the rectifying tube used. Preliminary information indicated the "propane" in question to be very nearly pure, and on this account a small volume was used and the plain tubes were employed. The sample contained only traces of methane and butane and a small percentage of ethane. The purities of the distillates were determined by the differential manometer method and the equations already mentioned.

Note on liquid samples.-It is quite possible to withdraw liquid samples from stills or other units of a "stablizing" or processing cycle and subject these to separation. Care should be taken to preserve the integrity of the liquid samples, since these have been found to fractionate during sampling. If the sample is withdrawn from a still under pressure, the valve admitting the sample to the receiver should be immersed in the still liquid itself and not placed outside the still shell at atmospheric temperature. The sample may be transferred to a small evacuated bulb of known volume and transferred directly to the evacuated distillation apparatus by condensation at liquid air temperatures. If the sample is entirely volatilized at room temperature, however, it is more convenient to sample and measure in the vapor phase.

The separation of liquid samples is best conducted by using the rectifying tube, as in chart 5 , except that a greater number of ditillations should be made from these tubes and fewer from the plain tubes. The method has already found success in at least one commercial laboratory.

Fractionation chart No.7 ( fig. 21). - The proper interpretation of data obtained in the development of plant processes often requires a knowledge of the complete composition of a natural gas or special plant sample. While the entire separation is unnecessary for the determination of natural gasoline, it will be well to include a chart to 
illustrate the separation of the nitrogen-methane and ethane fractions in order to supplement and complete the other charts here given. A "wet" natural gas was chosen as offering the most difficult type of separation which may be encountered. The separation of a "dry" natural gas will be merely a simplification of this case, involving fewer distillations.

Since the course of the distillation must be followed with reference to the vapor-pressure data, it is necessary to insure the complete removal of nitrogen, which does not condense at any of the temperatures here used or normally available but which is held strongly in solution by the methane. Most of the nitrogen was removed by initial distillations at $-185^{\circ} \rightarrow-194^{\circ} \rightarrow-210^{\circ}$ with the pumps operating in series, and two following steps which include pumping for short periods during the second and third distillations, with condensing tubes held at $-210^{\circ}$ interposed between the pumps and distilling tubes.

The subsequent separations were made by employing temperatures which were lowered $10^{\circ}$ for each succeeding distillation, the initial temperatures selected being higher than desirable for a final separation but facilitating the removal of the more volatile component which is held in solution by relatively large amounts of the higher boiling fractions. Thus, the methane was separated by distillations at $-170^{\circ} \rightarrow-180^{\circ} \rightarrow-190^{\circ} \mathrm{C}$., and the ethane separated at $-130^{\circ} \rightarrow$ $-140^{\circ} \rightarrow-150^{\circ} \mathrm{C}$.

It will be noted that a temperature of $-210^{\circ} \mathrm{C}$. is necessary to reduce the vapor pressure of the methane fractions sufficiently to eliminate a measurable error which might result from methane left in the vapor phase above the residues of ethane and higher boiling components. This low temperature is obtained by reducing the pressure over the liquid air contained in the Dewar tubes surrounding the distilling tubes. Liquid air so cooled is apt to fracture a distilling tube if the latter is immersed directly from room temperature, since it apparently wets the glass immediately upon immersion, while liquid air boiling at atmospheric pressure does not. It is accordingly wise to precool the distilling tube with liquid air which is boiling at atmospheric pressure before immersing it in the liquid which has been cooled below its atmospheric boiling point.

\section{RECOMBINATION OF FRACTIONS FOR DETERMINA- TION OF NATURAL GASOLINE CONTENT}

\section{MEASUREMENT OF PENTANE FRACTION}

The pentanes, together with heavier hydrocarbons, may be determined in the vapor phase simply by difference, or measured directly in the liquid phase. One method serves as a check on the other, and while the direct measurement is to be considered the more accurate 
for purposes of computing natural gasoline per million cubic feet of gas, the vapor phase calculation has been found sufficiently accurate for most engineernng needs and involves one less analytical operation.

If the liquid volume is determined, the special weight burette (fig. $3, B_{1}$ of fig. 10) is used. The pentane-plus condensate will be in either of the distilling tubes $I$ or $I I$ at the end of the fractional distillation. It is transferred to bulb 12 of the weight burette (see fig. 3) by vaporization and condensation at liquid air temperatures, stopcocks 31 and 32 being opened for this purpose.

The weight burette is described in detail in the reference previously cited. $^{20}$ For the operator's convenience the technique of operation may be outlined here. Reference is made to Figure 3.

The two bulbs 8 and 12 are accurately calibrated between etch marks 7 to 10 and 9 to 13 . The volume of 8 slightly exceeds that of 12, which in turn represents a slight excess over the maximum volume to be determined. When measuring a condensate, these bulbs are immersed in water bath 16 resting on a movable platform. The lower outlets of the bulbs are brought up over the edge of the water bath and thence down to 2-way cock 14 and $Y$ cock 15. Mercury is supplied to the system from the auxiliary glass stoppered reservoir 4 and drained from the system through outlet $1 \%$. The upper outlets of the bulbs terminate in 2-way cocks 2,3 , and 6 , which correspond to cocks 36, 33, and 32, respectively, of the assembly diagram. (Fig. 10.)

The capillary leads interconnecting the bulbs and various stopcocks are of $0.5 \mathrm{~mm}$ bore. Larger bores tend to trap gas at the tops of the siphons. Furthermore, the adjustment of liquid menisci to etch marks in a tube of such small diameter results in a high accuracy.

Before making a volume measurement the capillary leads connecting reservoir 4 and bulbs 8 and 12 and drain tube 17 are filled with clean mercury introduced at 4 , care being taken to avoid trapping any air. Mercury is then adjusted to etch mark 13 by connecting 4 to 12 through cock 15 . Final accurate adjustment of the mercury column is obtained by turning cock 2 to the vacuum line and cracking needle valve 11 to admit just sufficient pressure to reservoir 4 to allow the mercury to creep slowly upward to the etch mark. The water bath is removed and liquid air brought, around bulb 12 in order to transfer the condensate from tubes $I$ or $I I$. Stopcock 6 is then closed, the bulb allowed to rise to room temperature, whereupon the water bath is replaced. Mercury from 4 is now allowed to flow through cocks 14 and 15 to fill bulb 8 to etch mark $\%$. This measured volume of mercury is then admitted from bulb 8 through 14 and 15 into bulb 12 . The flow from bulb 8 is stopped when the meniscus of the pentane

${ }^{20}$ See footnote 7, p. 1152. 
condensate reaches etch mark 9 of bulb 12. The mercury remaining in 8 is then drained through cock 14 and drain $1^{17}$ in to a weighed flask, the flow being arrested when the mercury meniscus reaches etch mark 10 of bulb 8 . The tip of drain 17 should be immersed in a dish of mercury just previous to this drainage and withdrawn just before the weighing flask is placed. The tip is then immersed in the outflowing mercury, and if etch mark 10 is overrun the mercury may be redrawn into the burette from the flask by applying vacuum through stopcock 3. The mercury drained from 8 is weighed to $0.5 \mathrm{mg}$. The temperature of the water bath is observed.

The foregoing data are sufficient to calculate the volume of the pentane condensate (at the observed temperature) confined above the mercury in 12:

(Volume of 8 )-(volume represented by weight of mercury remaining in 8 and drained therefrom for weighing)=(volume of mercury admitted to 12).

(Volume of 12) $-($ volume of mercury admitted to 12$)=($ volume of condensate in 12, which was desired).

The volume of the pentane condensate may then be corrected to $0^{\circ} \mathrm{C}$. by applying the coefficient of expansion of pure pentane. Although the condensate is a mixture of pentane with the heavier hydrocarbons, this step introduces no appreciable error. In fact, the correction to $0^{\circ} \mathrm{C}$. may in some cases be unnecessary and was actually not fully applied in the present work, since the volumes of pentane condensate obtaining from the original gas volumes used were so small that the correction was usually small. In the event volumes larger than $0.1 \mathrm{ml}$ are obtained, the proper technique would be to conduct the measurements of liquid volumes at $0^{\circ} \mathrm{C}$., thereby automatically eliminating the necessity for such corrections. This technique should always be applied in the case of gases containing large amounts of natural gasoline condensate and whenever the best accuracy obtainable is desired.

The method may appear roundabout at first glance, but it will be noted that it eliminates errors which might be caused by wetting of the walls of bulb 12 by the condensate and the consequent impossibility of confining this liquid completely above the mercury.

The burette is prepared for a second measurement by slowly withdrawing the mercury from 12 , care being taken that no pentane condensate creeps into the capillary below etch mark 13. The condensate may be pumped off or vaporized and recondensed in the distillation train.

The burette is capable of measuring the volume of the condensate to within $0.001 \mathrm{ml}$, which represents an accuracy of well under 10 gallons of natural gasoline per million cubic feet of gas, if a gas sample as large as 1 liter is taken. Each $0.001 \mathrm{ml}$ of condensate per 
liter of sample corresponds to 7.480 gallons per million cubic feet. Consequently, when the liquid volume of a condensate is measured, it is recalculated according to the equation

Where

$$
G=\frac{N_{1}}{N_{2}}(7,480)
$$

$G=$ gallons per million cubic feet, $N_{1}=\mathrm{ml}$ of condensate determined, $\mathrm{N}_{2}=$ liters of gas sample taken.

In order to conform with the practice of the industry, $N_{1}$ should be measured at $0^{\circ} \mathrm{C}$. and $N_{2}$ at $60^{\circ} \mathrm{F}$., 30 inches $\mathrm{Hg}$. In the present work the reported values are for gas volumes measured at $0^{\circ} \mathrm{C}, 760$ $\mathrm{mm} \mathrm{Hg}$, dry.

\section{ADDITION OF BUTANE FRACTION}

The butane fraction, which has been measured and stored in the burette $B_{2}$ (fig. 10), may now be subdivided roughly into several parts and recombined with the condensate of pentane and heavier hydrocarbons.

The first procedure in this final step of the analysis is the transference of the pentane fraction to the condensing bulb $C_{2}$ of the vapor pressure manometer $M_{6} . \quad C_{2}$ is then surrounded with a water bath held at $100^{\circ} \mathrm{F}$. (or any other fixed temperature that may be desired). The vapor pressure of the pentane fraction is then observed, care being taken to attain the proper equilibrium. (The volume of the vapor phase must be negligible in order that the maximum saturation pressure of the mixture be obtained. See previous discussion, Sec. V, 6, last paragraph.) Bulb $C_{2}$ is then again immersed in liquid air and connected to the burette through stopcocks 57, 28, 27, 26, and 24 in series. A portion (roughly one-tenth of the total volume) of the butane is thus transferred from the burette and combined with the pentane fraction. The volume of this transferred portion is measured by noting the loss in volume from the burette. The new condensate in $C_{2}$ is then surrounded with the $100^{\circ} \mathrm{F}$. bath. After insuring equilibrium by vigorous stirring the increased vapor pressure is observed. If the operator so desires, this condensate may be transferred to the weight burette $B_{1}$ and its liquid volume measured. It is then recondensed in $C_{2}$, and a second measured portion of the butane remaining in burette $B_{2}$ is condensed into it, the increased vapor pressure of this second new mixture being observed at the same fixed temperature. In this manner data are obtained to show the change of vapor pressure (at the fixed temperature) dependent on the percentage of butane recombined with the original pentane fraction. A curve plotted from these data will reveal at a glance the maximum 
amount of hydrocarbon condensate possessing any selected vapor pressure, over the range determined and at the temperature fixed, which it is possible to extract from the natural gas so examined. A number of such curves are given in the following section and their analytical significance discussed.

A possible modification of the method naturally suggests itself at this point. If a supply of pure normal butane were available, it would be necessary to make only one complete separation by the fractional distillation method previously described. The gas sample might simply be separated into butane plus lower boiling components and pentane plus higher boiling components. The auxiliary supply of pure butane could then be combined with the pentane fraction in exactly the same manner as described above. Since pure normal butane might be more easily prepared in a large plant rectifying column than by quantitative separation in a laboratory apparatus, the suggestion here given seems practicable. It is evident that such a method could not be used if the amount of butane in the original gas sample were insufficient to raise the vapor pressure of the pentane fraction to the required value. However, most natural gases contain more than enough butane for this purpose, and the method would be applicable in the majority of cases. Justification for its use could be predetermined in many cases where a number of related samples were to be tested.

\section{ANALYTICAL RESULTS AND ACCURACY OBTAINABLE}

\section{VAPOR-PRESSURE CURVES OF MIXTURES OF PENTANE AND BUTANE FRACTIONS AND THEIR ANALYTICAL SIGNIFICANCE}

In order to illustrate how the data obtained by measurements of the percentages in the vapor phase are recalculated to gallons of condensate per million cubic feet of gas, a number of typical curves are reproduced in Figure 22. These cases cover the range from a natural gas containing small percentages of. pentane and heavier hydrocarbons to one containing large percentages of the higher boiling hydrocarbons. The fractionation charts of four of the gases studied have been given, and the curves are marked to correspond to the fractionation chart numbers. Thus, $C_{3}$ is the inlet gas of the extraction plant, the exit gas of which is $C_{4}$.

Referring to Figure 22, it will be noted that there are two curves for each gas. The curves marked with symbols which include the subscript $\mathrm{v}$ follow observed points. These points are indicated by open circles and represent the results of measurements in the vapor phase. The abscissas of these curves are expressed in terms of per cent by volume of condensable hydrocarbon vapor (pentane fraction plus butane) in the natural gas and are noted at the bottom of the sheet. 
The curves marked by symbols which include the subscript ${ }_{L}$, the observed points of which are indicated by crossed circles, represent data obtained by measurements of the liquid phase. Their abscissas are expressed directly in gallons of condensate per million cubic feet of gas and are noted at the top of the sheet. The ordinates of both

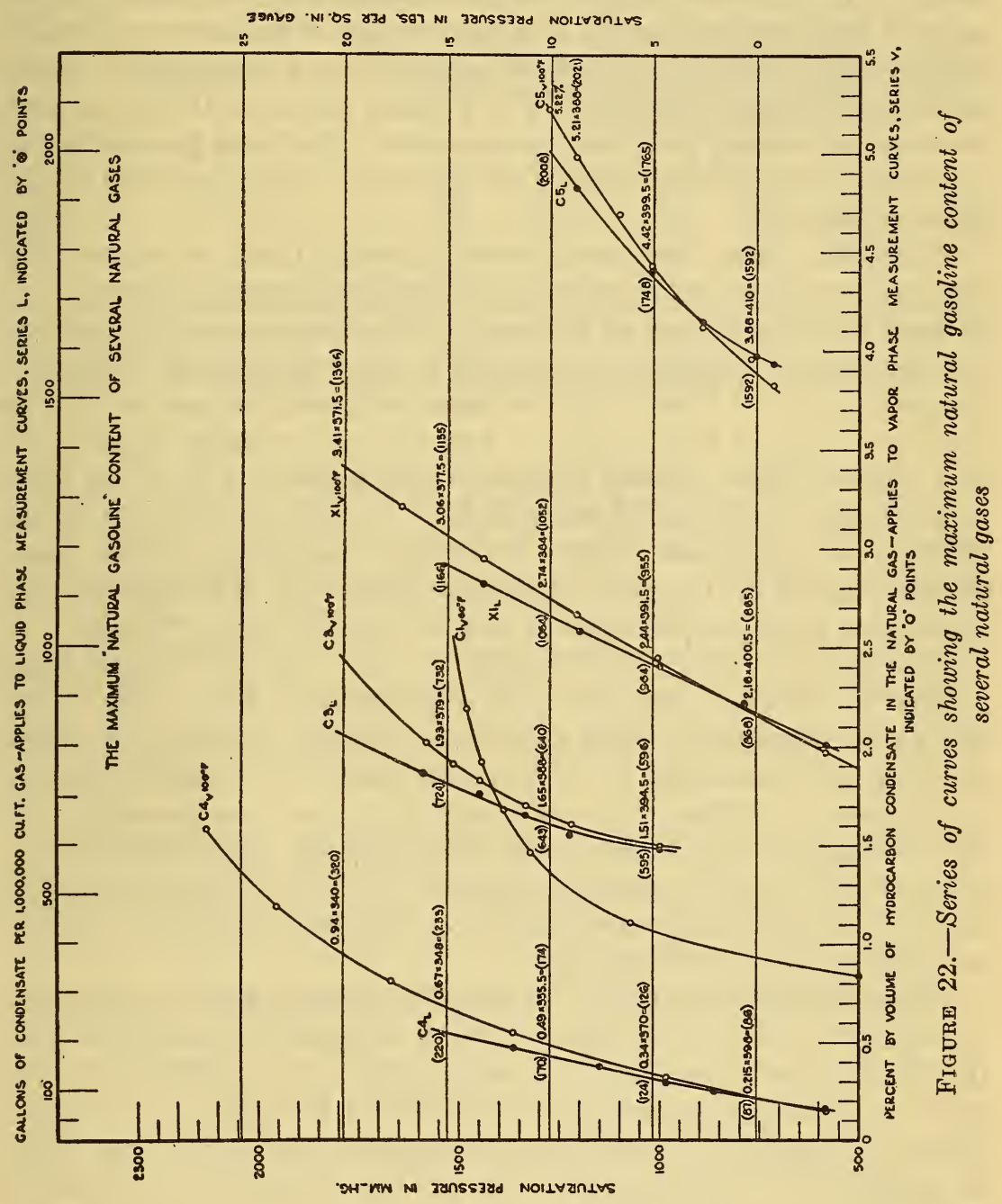

series of curves are expressed in saturation pressures, the scale at the left of the sheet being in $\mathrm{mm}$ of $\mathrm{Hg}$ and that at the right of the sheet in pounds per square inch gauge.

Consider, first, the series V, or vapor phase measurement curves, and take as an example the curve $C 4 \mathrm{~V}\left(100^{\circ} \mathrm{F}\right.$.). The lowest point on this curve has an abscissa 0.15 and an ordinate 585 . 
This means that the pentane fraction which was separated from this gas consisted of 0.15 per cent by vapor volume of the total gas sample and possessed a vapor pressure of $585 \mathrm{~mm} \mathrm{Hg}$ at $100^{\circ} \mathrm{F}$. The second point of this curve has an abscissa 0.32 and an ordinate 985. This means that a portion of the pure butane fraction consisting of 0.17 per cent of the total gas sample has been added to the pentane fraction, making the total percentage of this new condensate equal to 0.32 per cent of the whole gas sample and increasing its vapor pressure to $985 \mathrm{~mm} \mathrm{Hg}$ at $100^{\circ} \mathrm{F}$. Further points on the curve were obtained by adding measured percentages of the pure butane to the condensates and noting in order the increased vapor pressures at the same temperature.

When the curve has been drawn through these experimentally determined points, its intersections with the pressure abscissas may be read and interpreted as follows: The maximum possible amount of hydrocarbon condensate possessing a vapor pressure of $10 \mathrm{lbs}$./in. ${ }^{2}$ (gauge) at $100^{\circ} \mathrm{F}$. which may be extracted from this gas is 0.49 per cent by volume of the total gas. Any mixture occurring in excess of 0.49 per cent must possess a higher vapor pressure and would have to be shipped as "casing-head gasoline" according to the Interstate Commerce regulations. The maximum percentages have been similarly noted on the curve at intersections with the abscissas corresponding to vapor pressures of $0,5,15$, and $20 \mathrm{lbs}$./in. ${ }^{2}$ gauge.

The curves $C 3_{V} 100^{\circ} \mathrm{F}$, $X 1_{V} 100^{\circ} \mathrm{F}$, and $C 5_{V} 100^{\circ} \mathrm{F}$ have been drawn in the same manner from experimental data. The curve $C 1_{\nabla} 60^{\circ} \mathrm{F}$. represents a series of condensates, the saturation pressures of which were measured at $60^{\circ} \mathrm{F}$. rather than $100^{\circ} \mathrm{F}$. and illustrates a characteristic difference to be expected at lower temperatures. If the investigator is not concerned with shipping regulations but has in mind some specific product designed to meet individual needs, he may, of course, examine such a series of condensates over any desired range of temperatures or pressures.

The natural-gas engineer is interested in knowing how many gallons of condensate may be obtained per unit volume of natural gas, and the percentages expressed in the vapor phase do not directly reveal this. If the exact percentage composition of the pentane fraction is known, the gallons of condensate per million cubic feet of gas might be calculated for this fraction and for the subsequent mixtures of this with the increments of pure butane. However, the separation of the pentane fraction is impractical in the present instance, not only because of the closeness of the boiling points of its components but also because of the fact that the amount of condensate available for fractionation is extremely small. While the separation is not impossible, it is not to be considered in the present work. 
Another method of attack seems fairly simple. This follows from the consideration of the data tabulated below, which gives the volume relations of vapor and liquid phases for butane, pentane, hexane, and heptane.

TABLE 1.-Volume relations of vapor and liquid phases

\begin{tabular}{|c|c|c|c|c|c|c|}
\hline Hydrocarbon & $\begin{array}{l}\text { Density } \\
\text { of liquid } \\
\left(0^{\circ} \mathrm{C} .\right) \\
\text { (I. C. T. })\end{array}$ & $\begin{array}{c}\text { Molecu- } \\
\text { lar weight }\end{array}$ & $\begin{array}{l}\text { Weight } \\
\text { of a nor- } \\
\text { malliter } \\
\text { of vapor } \\
\text { (calcu- } \\
\text { lated) }\end{array}$ & $\begin{array}{l}\text { Vapor } \\
\text { volume } \\
\text { which } \\
\text { condenses } \\
\text { to } 1 \text { vol- } \\
\text { ume of } \\
\text { liquid }\end{array}$ & $\begin{array}{l}\text { Cubic } \\
\text { feet of } \\
\text { vapor } \\
\text { condens- } \\
\text { ing to 1 } \\
\text { gallon of } \\
\text { liquid }\end{array}$ & $\begin{array}{l}\text { Gallons } \\
\text { per } 10,000 \\
\text { cubic feet } \\
\text { of vapor }\end{array}$ \\
\hline $\begin{array}{l}\text { Butane } \\
\text { Pentane } \\
\text { Hexane } \\
\text { Heptane.... }\end{array}$ & $\begin{array}{l}0.601 \\
.64537 \\
.6769 \\
.70048\end{array}$ & $\begin{array}{c}58.08 \\
72.096 \\
86.112 \\
100.128\end{array}$ & $\begin{array}{l}2.591 \\
3.216 \\
3.842 \\
4.467\end{array}$ & $\begin{array}{l}232.0 \\
200.7 \\
176.2 \\
156.8\end{array}$ & $\begin{array}{l}31.02 \\
26.83 \\
23.56 \\
20.96\end{array}$ & $\begin{array}{l}322 \\
373 \\
425 \\
477\end{array}$ \\
\hline
\end{tabular}

Nоте.-The vapor volumes in the foregoing table are all measured at $0^{\circ} \dot{\mathrm{C}}_{.}, 760 \mathrm{~mm} \mathrm{Hg}$. The final column then expresses gallons of condensate at $0^{\circ} \mathrm{C}$., per 10,000 cubic feet of dry vapor at $0^{\circ} \mathrm{C} ., 760 \mathrm{~mm} \mathrm{Hg}$. If the natural-gas engineer desires to convert the butane factor to gallons ( $0^{\circ} \mathrm{C}$.) per 10,000 cubic feet at $60^{\circ} \mathrm{F}$., 30 inches $\mathrm{Hg}$, the figure 305 should be used instead of 322 and should be applied as shown in the following discussion.

Since the gallons of condensate are usually reported per unit volume of $1,000,000$ cubic feet of gas, the figures in the last column of this table represent the gallons of condensate which each hydrocarbon would yield if present to the extent of 1 per cent by volume in the total gas. In the light of these data it will be seen that appreciable error must result if an average factor is chosen to convert per cent by volume to gallons per million cubic feet. Such a conversion factor must depend not only on the actual initial composition of the pentane fraction but also upon the percentage of butane added at any step.

If, however, the actual liquid volume of the pentane fraction is measured by means of the weight burette $\left(B_{1}\right)$, the calculation may be made to follow rather closely the change in percentage composition of the successive condensates. For example consider again the curve $C 4 \mathrm{v}$. The volume of the pentane fraction of this gas measured in the liquid phase was found to be 64.5 gallons per million cubic feet. This corresponded to 0.15 per cent by volume in the vapor phase. If this condensate had occurred to the extent of 1 per cent by volume of the total gas, the amount of condensate would have been 430 gallons per 1,000,000 cubic feet. For each 1 per cent by volume of butane existing as vapor in the total gas 322 gallons per 1,000,000 cubic feet might be condensed. If a line is now drawn with percentages of butane from 0 to 100 as abscissas and gallons per 1,000,000 cubic feet as ordinates, with the values 0 per cent butane $=430$ gallons per $1,000,000$ cubic feet and 100 per cent butane $=322$ gallons per $1,000,000$ cubic feet, the figures for gallons per $1,000,000$ cubic feet corresponding to any percentage of butane in the mixture for each per cent of mixture present in the total gas may be read. 
This has been done in Figure 23, of which the line $C_{4}$ refers to the sample under discussion. Referring back to curve $C_{4 \mathrm{~V}}$ of Figure 22, the second experimental value noted is for a mixture representing 0.32 per cent of the total which was obtained by adding 0.17 per cent of butane to the 0.15 per cent of pentane-plus. The percentage of butane in this mixture is $0.17 / 0.32=42$. Reading from $C_{4}$ of Figure 23, the value corresponding to 42 per cent of butane is 385

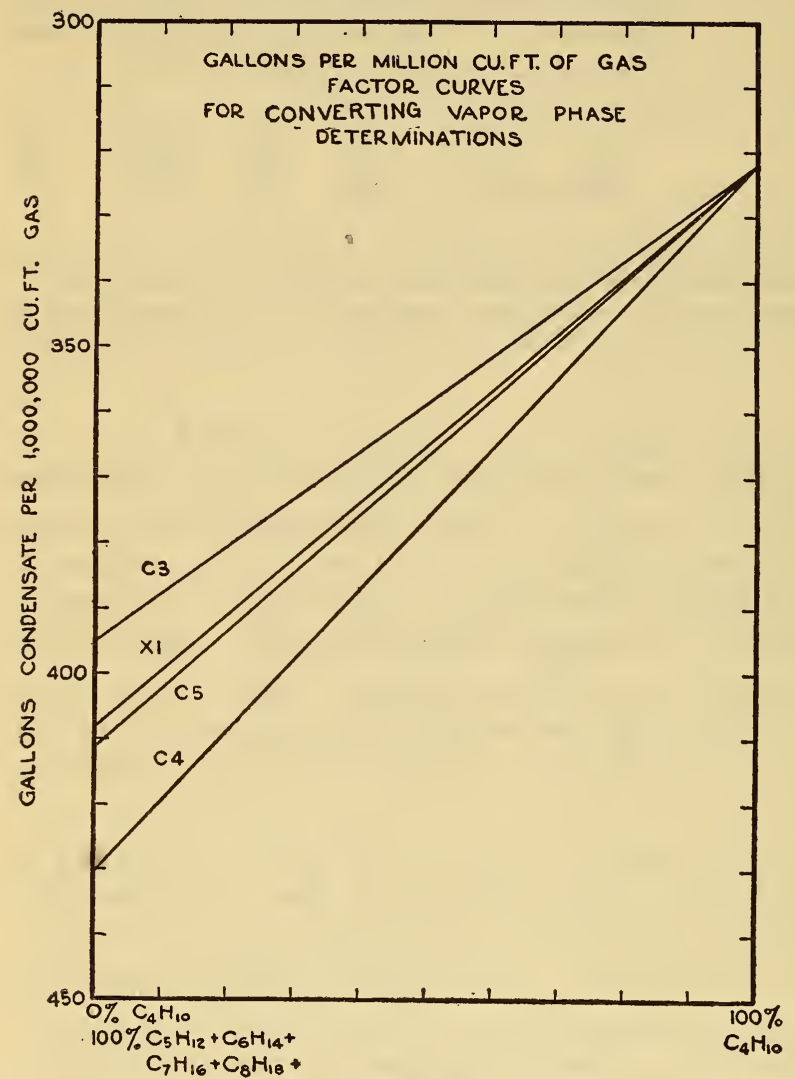

Figdre 23.-Factor curves for calculating vapor phase determinations ing order: Per cent condensate $\times$ conversion factor $=$ gallons per million cubic feet. It may be noted in passing that the value of the saturation pressure for the pentane fraction of curve $C S_{V}$ indicates the presence of some butane in this residue.

The ultimate accuracy of this method will be limited by the precision of the separation by distillation. With a great deal of care a precision of 0.02 per cent of the total volume can be attained which (in the case of 1 liter of sample) would correspond to an accuracy of about 8 gallons per million cubic feet for the average condensate 
having a vapor pressure of $10 \mathrm{lbs}$./in. ${ }^{2}$ Other sources of error are the incorrect measurement of gas volumes (negligible if a proper burette is used), failure to attain equilibrium in measuring vapor pressures (which may cause considerable errors), and the error in measurement of the liquid volume of the pentane condensate. The latter may result in an error of about the same magnitude as that arising from the limit of accuracy of the analytical separations.

\section{COMPARISON OF MEASUREMENT OF NATURAL GASOLINE CON- TENT AS DETERIMINED IN VAPOR AND LIQUID PHASES}

The natural gasoline content may be directly measured by means of the special weight burette. This method will eliminate some of the errors of the calculation from vapor phase measurements. The dependence upon the accuracy of the separation disappears, except that it is still absolutely essential that the butane fraction used shall contain no traces of propane or isobutane. The limiting accuracy lies in the measurement of the liquid volumes, and since this may be made to $0.001 \mathrm{ml}$ the figure representing gallons per million cubic feet should be correct to within 7.48 if a liter sample of gas is taken. This direct measurement is accordingly to be recommended when best results are sought. The objection offered by the method is simply that a volume measurement requires care and a considerable amount of time, so that by comparison the procedure is both more complicated and time consuming.

A number of these direct determinations of the liquid volumes of the condensates were made. The experimental data are noted on the series $C_{L}$ curves of Figure 22. The experimentally determined volumes were converted to gallons per million cubic feet. The plotted values are noted by the crossed circles. These curves form the basis for a direct comparison between the two methods of determining the natural gasoline content. The data are tabulated in Tables 2 and 3.

At the beginning of this work the Natural Gas Association Gasoline Committee named an accuracy of 10 gallons per million cubic feet as being entirely satisfactory for all purposes. A study of the data of Tables 2 and 3 shows that the calculation from vapor-phase data checks the direct measurement in the liquid phase within the limits required by the natural-gas engineer. The greatest difference noted between the two methods in the case of corresponding experimental values (Table 2) was 13 gallons per million cubic feet, and deviations from the average of the differences were all under 10 gallons per million cubic feet. In the case of values read from curves constructed from the experimental data (Table 3), the greatest difference noted was 17 gallons per million cubic feet, and the maximum deviation from the average of the differences was 10 gallons per million cubic feet. If all the values of Table 2 are considered, the average deviation 
between the two methods becomes +1 gallon per million cubic feet. It seems safe to assume that the vapor-phase method, which is the shorter of the two, will satisfy the demands of all ordinary engineering calculations.

TABLE 2.-Comparison of natural gasoline content obtained from direct measurement in liquid phase and calculated determination in vapor phase-Experimental values

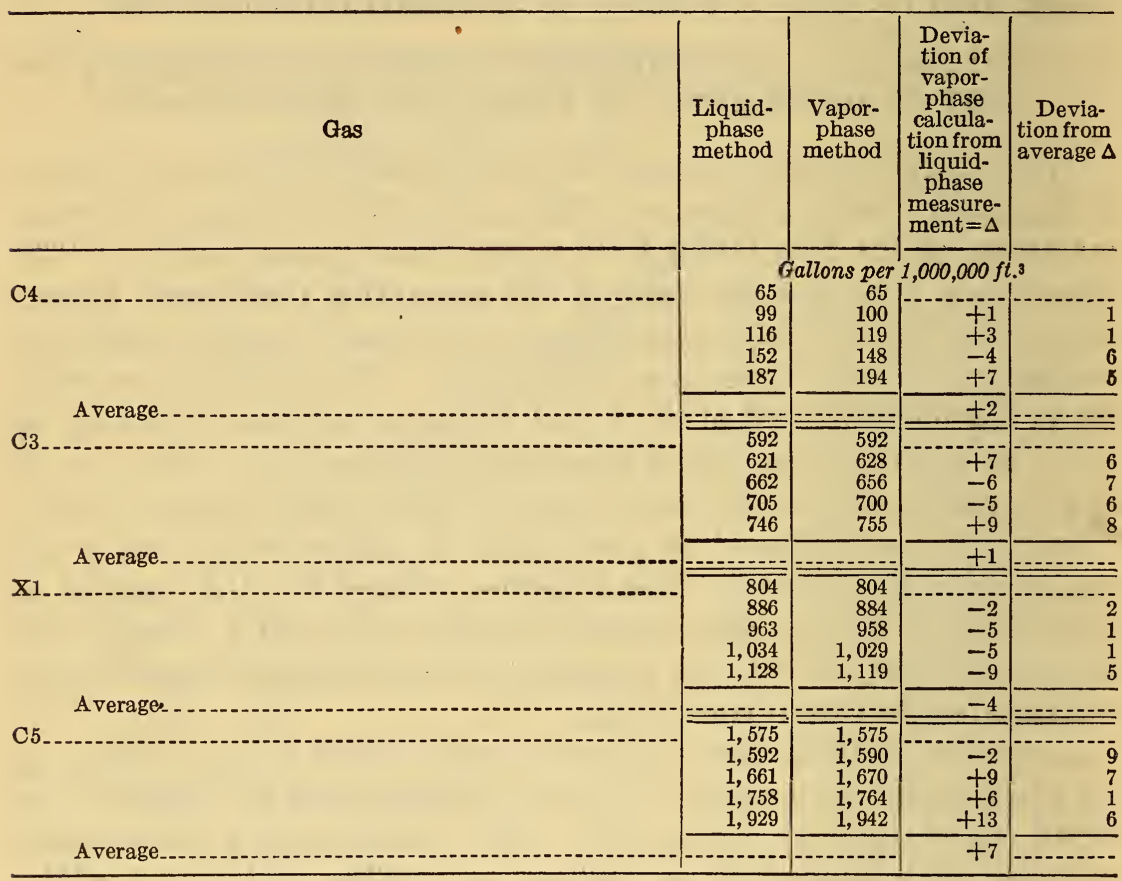

TABLE 3.-Comparison of natural gasoline content obtained from liquid-phase and vapor-phase methods-Values read from $C_{V}$ and $C_{L}$ curves

\begin{tabular}{|c|c|c|c|c|c|}
\hline \multirow[t]{2}{*}{ Gas } & $\begin{array}{l}\text { Vapor- } \\
\text { pressure } \\
\text { gauge }\end{array}$ & $\begin{array}{l}\text { Liquid- } \\
\text { phase } \\
\text { method }\end{array}$ & $\begin{array}{l}\text { Vapor- } \\
\text { phase } \\
\text { method }\end{array}$ & $\Delta$ & $\begin{array}{l}\text { Devia- } \\
\text { tion from } \\
\text { average } \Delta\end{array}$ \\
\hline & Lbs./in.2 ${ }^{2}$ & \multicolumn{2}{|c|}{ Gallons per } & $1,000,000 \mathrm{ft}$ & $3^{3}$ \\
\hline C4 & & $\begin{array}{r}87 \\
124\end{array}$ & $\begin{array}{r}86 \\
126\end{array}$ & $\begin{array}{r}-1 \\
+2\end{array} \mid$ & \\
\hline & 10 & 170 & 174 & +4 & \\
\hline & 15 & 220 & 233 & +13 & \\
\hline & & $-\ldots-\ldots$ & 320 & $-\ldots . . .-\ldots$ & \\
\hline A verage & $\ldots$ & $-\ldots$ & $-\ldots$ & +5 & $-\ldots$ \\
\hline \multirow{2}{*}{ C3 3} & 5 & 595 & $\overline{596}$ & $\overline{+1}$ & \\
\hline & $\begin{array}{l}10 \\
15\end{array}$ & $\begin{array}{l}643 \\
724\end{array}$ & $\begin{array}{l}640 \\
732\end{array}$ & $\begin{array}{l}-3 \\
+8\end{array}$ & \\
\hline A verage & $\ldots . . . . .$. & $=----\cdots$ & $\ldots$ & +2 & $=-\ldots \ldots$ \\
\hline \multirow{3}{*}{ 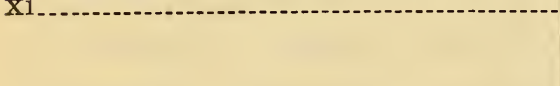 } & 0 & 868 & 865 & -3 & \\
\hline & 5 & 964 & 955 & -9 & \\
\hline & 10 & $\begin{array}{l}1,064 \\
1,166\end{array}$ & $\begin{array}{l}1,052 \\
1,155\end{array}$ & -8 & \\
\hline \multirow{2}{*}{ Average } & 20 & & 1,266 & 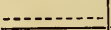 & $-\cdots \cdot-$ \\
\hline & $\ldots \ldots$ & $-\ldots \ldots$ & $\ldots$ & -8 & $-\ldots \ldots$ \\
\hline \multirow{2}{*}{ C5 } & 0 & 1,592 & 1,592 & & 10 \\
\hline & $\begin{array}{r}5 \\
10\end{array}$ & $\begin{array}{l}1,748 \\
2,008\end{array}$ & $\begin{array}{l}1,765 \\
2,021\end{array}$ & $\begin{array}{l}+17 \\
+13\end{array}$ & \\
\hline A verage & 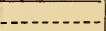 & ........ & $----2-4$ & +10 & $-\cdots$ \\
\hline
\end{tabular}




\section{COMPARISON OF RESULTS OBTAINED BY PRESENT METHODS WITH THOSE OBTAINED BY EXISTING FIELD AND LABORATORY METHODS}

It now remains to compare the analytical results obtained by the methods here described with those obtained by various existing field and laboratory methods. The latter comprise the oil absorption and charcoal adsorption methods in various modifications. Results reported for these field methods were obtained by members of the Gasoline Committee of the Natural Gas Association in connection with their standardization work.

The comparative data are assembled in Table 4. The first two columns of this table give the results of the methods here developed. The following columns give the reported results of the other methods for the same gases, together with their actual and percentage deviations from the new methods taken as standards. The figures reported for these tests are, in general, averages of an unreported number of tests. Check values reported for the same method are noted by braces. Otherwise, when more than one value is reported, the gas has been tested by several modifications of the same general method.

Only three cases occur in which the ordinary methods gave higher results than the new method. In all three cases the determination was made by the method of charcoal adsorption. Two of these three determinations yielded satisfactory checks with the proposed standard method; the third, which was 21.2 per cent high, is explained by the fact that the vapor pressure of the condensate obtained from the charcoal exceeded $10 \mathrm{lbs}$./in. ${ }^{2}$.

The closest checks observed between the ordinary and new methods were -2.0 and +2.2 per cent. The greatest discrepancies were approximately -55 per cent. The average deviation was approximately -26 per cent for the case of oil absorption and -23 per cent for the case of charcoal adsorption. (In obtaining these figures the braced values of Table 4 were not taken independently but averaged, and each set weighted as a single determination.) If the values for the gas $\mathrm{X} 6$ are excepted, the range of percentage deviation from the reference method is -2.0 to -42.2 per cent for oil-absorption tests and +21.2 to -44.5 per cent for charcoal-adsorption tests. There is apparently little justification for preferring one of these methods to the other when both are judged on the basis of these results.

There are three general conclusions to be drawn from the comparative data. The first is that different modifications of the same fieldlaboratory method yield results which do not always agree. The second is that no modification of the oil absorption method gives results which agree with any modification of the charcoal adsorption method. The third is that both the oil absorption and charcoal adsorption methods give results which are too low. 
TABLE 4.-Comparison of results obtained by methods described with those obtained by existing field and laboratory methods

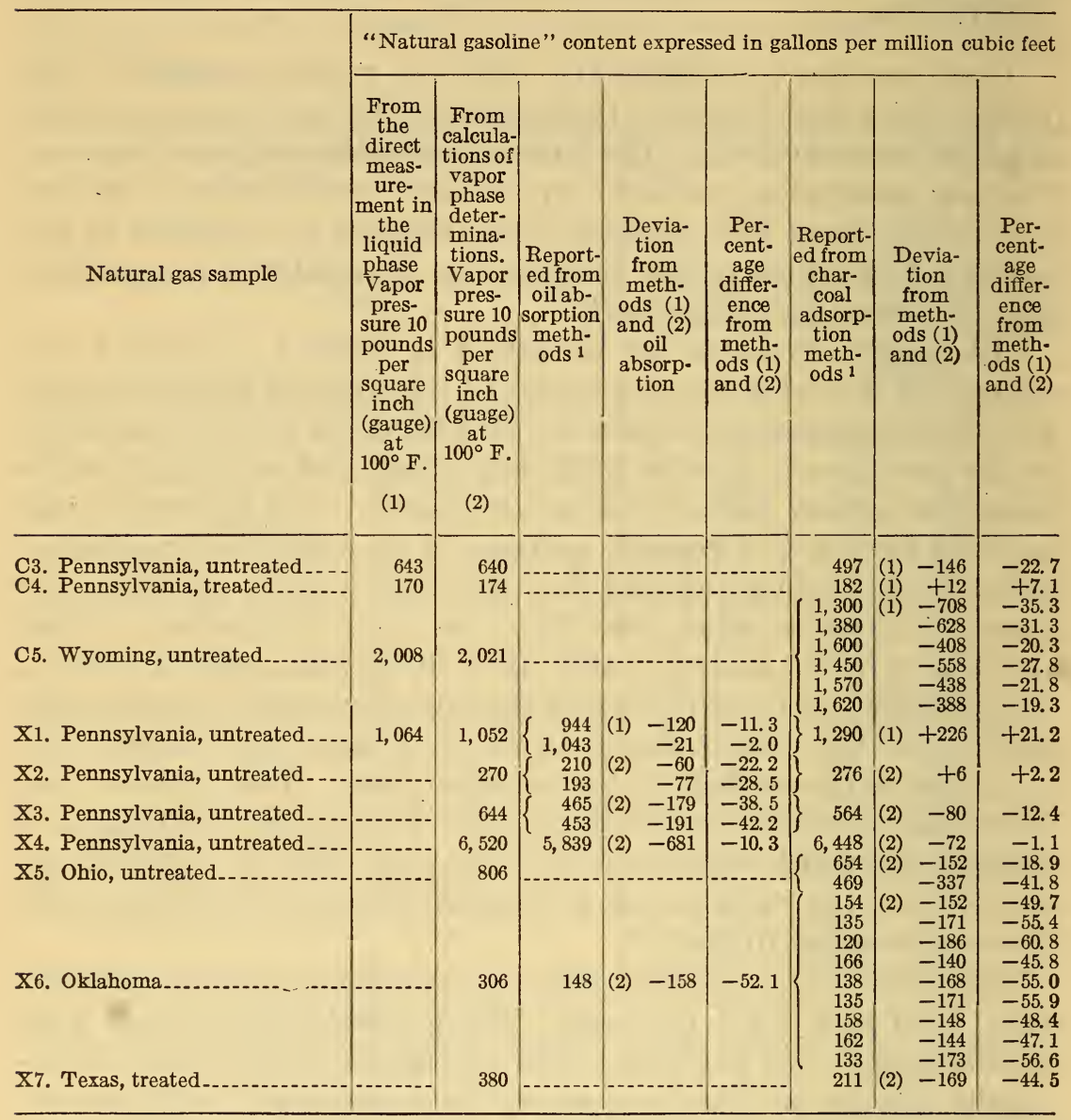

1 Figures are given for several modifications of the same method where available. Braced figures indicate check analyses obtained by identical procedure. Other figures are, in general, averages from an unreported number of determinations. The figures in parentheses indicate the method used.

All of these facts were to be expected, since the oil absorption and charcoal adsorption methods involve many variable factors, some of which are not readily controlled. Even a thorough standardization of these test methods can not entirely eliminate some of these variable factors, and back of these considerations lies this fundamental difficulty - the ordinary sorption methods seek to determine a substance which has no identity. The substance isolated by the test is called the thing sought. If this were entirely reproducible, the idea would be convenient. Since it is not, confusion must result. The results obtained by the new method can not be strictly compared with those yielded by the ordinary methods, since the new method isolates a perfectly definite condensate which can be analytically reproduced 


\section{CONCLUSION}

It has been shown that an exact definition of the term "natural gasoline" is a prerequisite to the determination of the actual natural gasoline content of a natural gas. A definition has been developed which describes the maximum amount of condensate, complying with shipping regulations, that can be extracted from a natural gas. A method has been developed for the accurate determination of natural gasoline thus defined. Analyses made by this proposed standard method have been compared with those made by the ordinary existing methods. The data obtained indicate that the natural gasoline content of a natural gas can only be determined by the use of such a method as the proposed standard one, since existing field and laboratory methods yield results which do not agree among themselves and, in general, are lower than values obtained by the standard method. It is further evident that the interpretation of experimental plant data, the determination of actual plant efficiencies, the study of the action of rectifying columns for the removal of propane from natural gasoline or for the production of special fractions from the natural gas condensates, and other special investigational problems must depend for their true solution upon such a reference method as here developed.

Washington, October 10, 1928 . 